\title{
Modeling and Simulation of the Off-gas in an Electric Arc Furnace
}

\author{
THOMAS MEIER, KARIMA GANDT, THOMAS ECHTERHOF (1), \\ and HERBERT PFEIFER
}

The following paper describes an approach to process modeling and simulation of the gas phase in an electric arc furnace (EAF). The work presented represents the continuation of research by Logar, Dovžan, and Škrjanc on modeling the heat and mass transfer and the thermochemistry in an EAF. Due to the lack of off-gas measurements, Logar et al. modeled a simplified gas phase under consideration of five gas components and simplified chemical reactions. The off-gas is one of the main continuously measurable EAF process values and the off-gas flow represents a heat loss up to 30 pct of the entire EAF energy input. Therefore, gas phase modeling offers further development opportunities for future EAF optimization. This paper presents the enhancement of the previous EAF gas phase modeling by the consideration of additional gas components and a more detailed heat and mass transfer modeling. In order to avoid the increase of simulation time due to more complex modeling, the EAF model has been newly implemented to use an efficient numerical solver for ordinary differential equations. Compared to the original model, the chemical components $\mathrm{H}_{2}, \mathrm{H}_{2} \mathrm{O}$, and $\mathrm{CH}_{4}$ are included in the gas phase and equilibrium reactions are implemented. The results show high levels of similarity between the measured operational data from an industrial scale EAF and the theoretical data from the simulation within a reasonable simulation time. In the future, the dynamic EAF model will be applicable for on- and offline optimizations, e.g., to analyze alternative input materials and mode of operations.

DOI: $10.1007 / \mathrm{s} 11663-017-1093-7$

(C) The Minerals, Metals \& Materials Society and ASM International 2017

\section{INTRODUCTION}

ELECTRIC steelmaking in an electric arc furnace $(\mathrm{EAF})$ is the main process route for steel scrap recycling and the second most important steel production route in the world. As an energy-intensive process, the EAF is responsible for approximately 3 pct of the total industrial electricity consumption and a significant lever for energy efficiency optimization. ${ }^{[1]}$ As the off-gas flow represents an energy output of 20 to 30 pct of the total EAF energy input, the off-gas is in the focus of current developments to increase the energy and resource efficiency of the EAF. As one of the main continuously measurable process values, the off-gas composition can be utilized to improve the process control and allows conclusions to be made concerning the process behavior. Here, process models have proven their applicability for process control and their capability to contribute toward a more detailed

THOMAS MEIER, KARIMA GANDT, THOMAS ECHTERHOF, and HERBERT PFEIFER are with the Department for Industrial Furnaces and Heat Engineering, RWTH Aachen University, Kopernikusstrasse 10, 52074 Aachen, Germany. Contact e-mail: echterhof@iob.rwth-aachen.de

Manuscript submitted March 24, 2017.

Article published online September 28, 2017. understanding of heat and mass transfer during the melting process. In times of continuously growing computational capacity, the complexity of the dynamic process simulation models has increased due to the consideration of more and more phenomena. Logar et al. ${ }^{[2-4]}$ presented a comprehensive deterministic EAF model, which is based on fundamental physical and mathematical equations. The model includes all main thermal, chemical, and mass transfer phenomena in the EAF. These are implemented via first-order ordinary differential equations (ODEs). It was further developed and enhanced with a more detailed simulation of the arc heat distribution and a modified chemical module..$^{[5,6]}$ Due to the lack of off-gas data from the validation furnace, the gas phase was simplified. Five chemical components are taken into account and chemical reactions are only considered for post-combustion. As one of the best recently published EAF models, it was found to be suitable a starting point for further development of the gas phase modeling, which is described within this paper, which is therefore a continuation of the work done by Logar et al.

A detailed literature review shows that there are other papers addressing the modeling of the gas phase in an EAF, but with different approaches and simplifications. Opitz and Treffinger ${ }^{[7]}$ use the model of Logar et al. to design a dynamic, physics-based model of a complete EAF 
plant which consists of four sub-systems (vessel, electric system, electrode regulation, and off-gas system). Matson and Ramirez ${ }^{[8,9]}$ consider six chemical elements in the off-gas and determine the reaction rates with a chemical equilibrium algorithm by Gibbs free energy minimization. The simulation calculation time is not mentioned and is assumed slow compared to other approaches. Furthermore, the results of the gas phase simulation are not compared to measured data and the curves show a constant behavior over long periods. MacRosty and Swartz ${ }^{[10]}$ consider all relevant species in the gas zone and assume chemical equilibrium in each zone. The model does not address gas radiation and requires a high computing capacity. Nyssen et al. ${ }^{[11]}$ published another EAF model. The model seems to include all major processes, but no details are given in the publication.

The objective of this work was to consider all major measurable gas components in an EAF process model. Therefore, in addition to $\mathrm{CO}, \mathrm{CO}_{2}, \mathrm{~N}_{2}, \mathrm{O}_{2}$, and $\mathrm{CH}_{4}$, the components $\mathrm{H}_{2}, \mathrm{H}_{2} \mathrm{O}$, and $\mathrm{CH}_{4}$ are also included in the gas phase of this study. The components are considered in chemical reactions for post-combustion, major equilibrium reactions, and dissociation. To prevent the increase of simulation time, the EAF model was newly implemented in MATLAB to use the internal ODE-solver instead of the fixed step Euler method, which was chosen by Logar et al.

The further development is based on an industrial scale $140 \mathrm{t}$ EAF. The operational data of the EAF are used for the model parametrization and final validation of the simulation results. The input powers and mass flows of the periphery are used as input data for the simulation. The simulation results are evaluated concerning off-gas composition, temperature, and energy.

\section{MODELING}

Within this section, the approach of modeling the off-gas is described as an enhancement to the EAF process model developed by Logar et al. ${ }^{[2,3]}$ Therefore, the paper follows the basic assumptions and simplifications as addressed in part $1^{[2]}$ and part $2^{[3]}$ of the EAF model publication from Logar et al., which are also valid for this enhanced model and will not be repeated in this paper. The EAF is divided into eight different zones:

(1) Solid scrap (sSc),

(2) Liquid scrap (1Sc),

(3) Solid slag ( $\mathrm{sSl})$,

(4) Liquid slag (1Sl),

(5) Gas phase (gas),

(6) Walls (wall),

(7) Electrode/s (el),

(8) Electric arc/s (arc)

Each zone and chemical component has assigned physical properties, i.e., specific heat capacity $C_{\mathrm{p}}$, density $\rho$, molar mass $M$, etc. The values used for the parameters are listed in Appendix in Table V.

Within and between the defined phases inside the EAF vessel, thermo-chemical reactions, as well as heat and mass transfer take place. Figure 1 gives a schematic overview of the enhanced model structure and the basic functioning.

\section{A. New Model Implementation}

To overcome the contradiction between simulation accuracy, simulation calculation time, and numerical integration time steps, the EAF model has been newly implemented to use efficient ODE-solving methods within the software MATLAB. While Logar et al. ${ }^{[2]}$ used a fixed step Euler method with a chosen time step of $10^{-4}$ seconds, numerical integration methods with a variable calculation of the integration time step have proven their efficiency to solve complex ODE-systems. ${ }^{[12]}$

The usage of the MATLAB ODE-solving methods required several model modifications. Sudden changes caused by if-else conditions were replaced by continuous algorithms to realize on/off behavior. In detail, the variable that has to be switched is multiplied with a modified hyperbolic tangent function, which results in values of zero and one with a continuous transition. Furthermore, the calculation of the melting geometry is performed by modeling the scrap heap as a body of revolution around the middle axis of the EAF. A variable angle of the borehole in the scrap is used to determine the geometrical data for the view factor calculation. ${ }^{[13]}$

As a consequence of mass transfer between the different phases, mixing temperatures have to be calculated. Because the step size is not directly known during the simulation, the calculation of the mixing temperature is directly integrated into the calculation of the temperature change rates. In a general way, this is determined according to Eq. [1]:

$$
\frac{\mathrm{d} T_{\mathrm{xx}}}{\mathrm{d} t}=\frac{\dot{Q}_{x x}-\left(T_{x x}-T_{\text {addition }}\right) C_{\mathrm{p}, \text { addition }} \dot{m}_{\text {addition }}}{m_{x x} C_{\mathrm{p}, \mathrm{xx}}} .
$$

A phase $x x$ (with mass $m_{x x}$, temperature $T_{x x}$, and heat capacity $\left.C_{\mathrm{p}, \mathrm{xx}}\right)$ changes its temperature due to adding a mass (with mass flow $\dot{m}_{\text {addition, }}$, temperature $T_{\text {addition, and }}$ heat capacity $C_{\mathrm{p} \text {,addition }}$ ) by the temperature rate $\frac{\mathrm{d} T_{x x}}{\mathrm{~d} t}$. The resulting net heat flow is $\dot{Q}_{\mathrm{xx}}$, which is positive or negative, depending on the temperature difference $\left(T_{x x}-T_{\text {addition }}\right)$. One example is the temperature change of the liquid steel melt (1Sc), which is calculated according to Eq. [2]:

$$
\begin{aligned}
\frac{\mathrm{d} T_{1 \mathrm{Sc}}}{\mathrm{d} t}= & \frac{1}{m_{\mathrm{lSc}} C_{\mathrm{p}, \mathrm{ISc}}}\left[\dot{Q}_{\mathrm{ISc}}-\dot{m}_{\mathrm{solidify}} \lambda_{\mathrm{sSc}}+\left(T_{\mathrm{ISc}}-T_{\mathrm{melt}, \mathrm{SSc}}\right) \dot{m}_{\mathrm{SSc}} C_{\mathrm{p}, \mathrm{ISc}},\right. \\
& \left.-\left(T_{\mathrm{lSc}}-T_{\mathrm{air}}\right)\left(\dot{m}_{\mathrm{O}_{2}-\text { lance }} C_{\mathrm{p}, \mathrm{O}_{2}}+\dot{m}_{\mathrm{C}-\mathrm{inj}} C_{\mathrm{p}, \mathrm{C}}\right)\right],
\end{aligned}
$$

where $\dot{Q}_{1 \mathrm{Sc}}$ denotes the net heat flow of the liquid melt, $\dot{m}_{\text {solidify }}$ represents a negative mass flow to the scrap if solidification occurs and $\lambda_{\mathrm{sSc}}$ is the latent heat of fusion, $\dot{m}_{\mathrm{sSc}}$ is the negative mass change rate of scrap, $\dot{m}_{\mathrm{O}_{2}-\text { lance }}$ and $\dot{m}_{\mathrm{C}-\text { inj }}$ are the injection of oxygen and carbon into the melt, and $T_{\mathrm{i}}$ are the corresponding temperatures with the ambient temperature $T_{\text {air }}$.

After the re-implementation, it was found that the ODE-system of the model is stiff. As the multi-step backward differentiation formula/numerical differentiation 


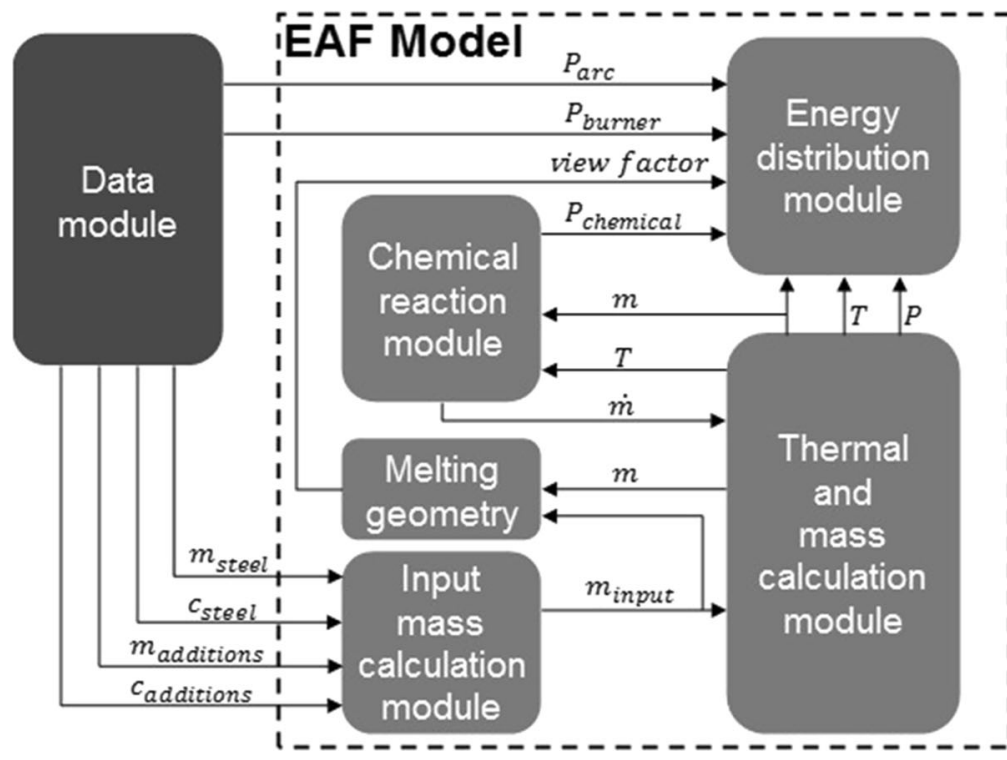

Simulation

results

Fig. 1-Structure and functioning of the EAF process model.

formula $(\mathrm{BDF} / \mathrm{NDF})$ solver ode15s is most suitable for stiff ODE-systems and delivered best results in terms of accuracy and speed, it was chosen for future developments. Further investigation on numerical solution methods for EAF modeling was done by Meier et al. ${ }^{[12]}$

\section{B. Relevant Chemical Off-gas Elements}

The gas phase (gas) in Logar's model consists of the five elements $\mathrm{CO}, \mathrm{CO}_{2}, \mathrm{~N}_{2}, \mathrm{O}_{2}$, and $\mathrm{CH}_{4}$, where total combustion of $\mathrm{CH}_{4}$ is assumed. ${ }^{[2,3]}$ Due to the fact that the $\mathrm{H}_{2} \mathrm{O}$ and $\mathrm{H}_{2}$ mass fractions reach significant values during off-gas composition measurements, whereby $\mathrm{CH}_{4}$ is detected in the off-gas as well, those elements are considered in the gas phase of the new enhanced EAF model using the following modifications. The mass flows of $\mathrm{H}_{2}, \mathrm{H}_{2} \mathrm{O}$, and $\mathrm{CH}_{4}$ into the EAF and their outflow due to the off-gas removal and blow out are described in the following section as well as the chemical reactions and the reaction enthalpies.

\section{Chemical Reactions}

A considerable amount of energy is required for steel production. This necessary thermal energy is provided by the electric arcs and by the conversion of chemical energy to thermal energy by oxidation reactions. ${ }^{[14]}$ The oxidizing reactants are mainly provided by the charged coal and the burners. However, there are also smaller amounts of reactants, e.g., due to electrode consumption and contaminants adhering to the scrap, such as paint or plastics. They are assumed to be nonane $\left(\mathrm{C}_{9} \mathrm{H}_{20}\right)$. Logar et al. ${ }^{[3]}$ defined 15 reactions (a) to (p) [(o) is missing] which are occurring in the liquid melt, the 1Sl, and the gas phase. The reaction equations (a) to (m) were adopted unchanged. The reactions concerning methane (n) and nonane (p) were slightly adapted and further reactions [from $(\mathrm{q})$ to $(\mathrm{u})$ ] were implemented for the gas phase. The altered and added reactions are listed in Eq. [3]:

$$
\begin{array}{r}
\left(\mathrm{n}_{1}\right) \mathrm{CH}_{4}+2 \mathrm{O}_{2} \rightarrow \mathrm{CO}_{2}+2 \mathrm{H}_{2} \mathrm{O}, \\
\left(\mathrm{n}_{2}\right) 2 \mathrm{CH}_{4}+3 \mathrm{O}_{2} \rightarrow 2 \mathrm{CO}+4 \mathrm{H}_{2} \mathrm{O}, \\
\left(\mathrm{n}_{3}\right) \mathrm{CH}_{4}+\mathrm{O}_{2} \rightarrow \mathrm{CO}_{2}+\mathrm{H}_{2}, \\
(\mathrm{p}) \mathrm{C}_{9} \mathrm{H}_{20} \rightarrow 9 \mathrm{C}+10 \mathrm{H}_{2}, \\
(\mathrm{q}) \mathrm{CO}+\mathrm{H}_{2} \mathrm{O} \leftrightarrow \mathrm{CO}_{2}+\mathrm{H}_{2}, \\
(\mathrm{r}) \mathrm{C}+\mathrm{CO}_{2} \leftrightarrow 2 \mathrm{CO}, \\
(\mathrm{s}) \mathrm{C}+\mathrm{H}_{2} \mathrm{O} \leftrightarrow \mathrm{CO}+\mathrm{H}_{2}, \\
(\mathrm{t}) \mathrm{H}_{2}+\frac{1}{2} \mathrm{O}_{2} \leftrightarrow \mathrm{H}_{2} \mathrm{O}, \\
(\mathrm{u}) \mathrm{C}+\frac{1}{2} \mathrm{O}_{2} \rightarrow \mathrm{CO},
\end{array}
$$

These reactions present the enhancement of the current models gas phase. They mainly effect the rates of change of elements and the calculation of reaction enthalpies. This is addressed in the following section.

\section{Equilibrium reactions}

Due to the typical temperatures in EAFs between 1273 $\mathrm{K}$ and $2273 \mathrm{~K}\left(1000^{\circ} \mathrm{C}\right.$ and $\left.2000{ }^{\circ} \mathrm{C}\right)$, equilibrium reactions as well as dissociation have to be considered in the modeling of the gas phase. While taking into account the elements of the gas phase and the presence of $\mathrm{C}$ in the EAF, the Boudouard reaction, Eq. [3r], as well as the homogeneous and heterogeneous water-gas shift reactions, Eqs. [3q] and [3s], are modeled. The reaction rates of these three reactions are calculated with the corresponding equilibrium constant, which for simplification is assumed to be only temperature-dependent and not composition-dependent. The molar reaction rate $r$ can be determined by Eq. [4], while the equilibrium constant $K_{c}$ is determined by the forward and backward reaction rate constant according to Eq. [5]. The mole concentrations $c_{i}$ are obtained using Eq. [6]. ${ }^{[i 5]}$ 


$$
\begin{gathered}
r=k_{\mathrm{f}} \prod_{i=1}^{I}\left[c_{i}\right]^{v_{i}^{\prime}}-k_{\mathrm{b}} \prod_{i=1}^{I}\left[c_{i}\right]^{v_{i}^{\prime \prime}}, \\
K_{\mathrm{c}}=\frac{k_{\mathrm{f}}}{k_{\mathrm{b}}} \\
c_{i}=\frac{m_{i}}{M_{i} V_{\mathrm{gas}}} .
\end{gathered}
$$

Here, $v_{i}^{\prime}$ and $v_{i}^{\prime \prime}$ represent the stoichiometric coefficients of the forward (') and backward (") reaction.

It is not possible to easily derive $k_{\mathrm{f}}$ and $k_{\mathrm{b}}$ from $K_{\mathrm{c}}$ or other data available to the model. Therefore, to be able to solve the equation, the backward reaction rate constant is assumed to be $k_{\mathrm{b}}=1$, leading to the simplified Eq. [7]. In addition, in Eq. [10] an empirical velocity coefficient is added.

$$
r=K_{\mathrm{c}} \prod_{i=1}^{I}\left[c_{i}\right]^{v_{i}^{\prime}}-\prod_{i=1}^{I}\left[c_{i}\right]^{v_{i}^{\prime \prime}}
$$

$K_{\mathrm{c}}$ can be determined by the idea of the free Gibbs energy minimization through Eqs. [8] and [9]:

$$
\begin{gathered}
K_{\mathrm{p}}=\exp \left(\frac{-\Delta_{\mathrm{R}} G^{0}}{R_{\mathrm{m}} T}\right)=\prod_{i}\left(\frac{p_{i}}{p^{0}}\right)_{\mathrm{e}}^{v_{i}}, \\
K_{\mathrm{c}}=K_{\mathrm{p}}\left(\frac{p^{0}}{R_{\mathrm{m}} T}\right)^{\sum v_{i}},
\end{gathered}
$$

where $K_{\mathrm{p}}$ is the standard equilibrium constant, $\Delta_{R} G^{0}$ represents the free standard enthalpy, $p^{0}$ is the pressure at standard conditions, $p_{i}$ is the partial pressure, and $R_{\mathrm{m}}$ is the molar gas constant.

The equilibrium constant $K_{\mathrm{c}}$ is pre-calculated for each of the three equilibrium reactions with the help of the chemical equilibrium toolbox MediumModel ${ }^{[16]}$ within MATLAB, based on the "NASA Glenn Coefficients for Calculating Thermodynamic Properties of Individual Species" and stored in a temperature-dependent database. The database is evaluated at each time step with a corresponding temperature to obtain the equilibrium constant $K_{\mathrm{c}-(\xi)}$ for the equilibrium reaction $[\xi=(\mathrm{q}),(\mathrm{r})$, and (s)]. The mass change for each element is then calculated using Eq. [10]:

$$
\frac{\mathrm{d} m_{i}}{\mathrm{~d} t}=r_{(\xi)} v_{i} V_{(\xi)} M_{i} \mathrm{kd}_{\text {gas }-(\xi)},
$$

where $V_{(\xi)}$ is the available volume for the reaction and $\mathrm{kd}_{\text {gas- }(\xi)}$ is an empirical velocity coefficient. These velocity coefficients either were taken from Logar et $a{ }^{[3]}$ or were developed during the parameterization of the modified model using the available operating data. They are listed in Table II in Appendix.

In contrast to the described equilibrium reactions above, the dissociation of $\mathrm{H}_{2} \mathrm{O}$, which is the reverse reaction of Eq. [3t], is modeled using a simplified empirical approach which is described later.

2. Rate of change of carbon (C)

Since carbon is involved in reactions within the gas phase, the equations of the carbon mass transfer were modified in comparison to those of Logar et al. ${ }^{[3]}$ In accordance with Logar and for a better overview, the mass flows of the respective elements $i$ are divided based on their physical-chemical cause. These individual mass flows are denoted by the variable $x i_{\mathrm{dj}}(j=$ number for the individual mass flow). With their summation, the net mass flow of the element $i\left(\dot{m}_{i}\right)$ is determined.

The rate of change of carbon is calculated for three different masses of $\mathrm{C}$ in the EAF: first, the mass of $\mathrm{C}$ present in the EAF $\left(m_{\mathrm{C}-\mathrm{L}}\right)$, second, the dissolved $\mathrm{C}$ in the liquid melt $\left(m_{\mathrm{C}-\mathrm{D}}\right)$, and third, the $\mathrm{C}$ from charge coal $\left(m_{\text {coal }}\right)$.

The following mechanisms are relevant for the mass of $\mathrm{C}$ in the $\operatorname{EAF}\left(m_{\mathrm{C}-\mathrm{L}}\right): \mathrm{C}$ is injected in the furnace $\left(x 1_{\mathrm{d} 1}\right)$. This injected $\mathrm{C}$ and the $\mathrm{C}$ present in the EAF are used in the decarburization of the melt $\left(x 1_{\mathrm{d} 2}\right)$. Furthermore, $\mathrm{C}$ is dissolved in the melt $\left(x 1_{\mathrm{d} 3}\right)$. $\mathrm{C}$ is formed during the dissociation of combustible material. This amount and the $\mathrm{C}$ from charged coal are available for further reactions $\left(x 1_{\mathrm{d} 4}\right)$. During the oxidation of $\mathrm{C}$ to $\mathrm{CO}$ with the oxygen of the gas phase $\left(x 1_{\mathrm{d} 5}\right)$ and with leak air $\left(x 1_{\mathrm{d} 6}\right), \mathrm{C}$ is used. Finally, $\mathrm{C}$ is taking part in the heterogeneous water-gas reaction Eq. [3s] $\left(x 1_{\mathrm{d} 7}\right)$. The rate of change of $\mathrm{C}$ present in the EAF $\left(\dot{m}_{\mathrm{C}-\mathrm{L}}\right)$ is given by Eq. [11]:

$$
\begin{aligned}
& x 1_{\mathrm{d} 1}=\dot{m}_{\mathrm{C}-\mathrm{inj}}, \\
& x 1_{\mathrm{d} 2}=\left(-\frac{\mathrm{kd}_{\mathrm{C}-\mathrm{L}} m_{\mathrm{FeO}} m_{\mathrm{C}-\mathrm{L}}^{0.75}}{m_{\mathrm{SS} 1}}-0.6 x 1_{\mathrm{d} 1}\right)\left(1-\frac{V_{\mathrm{sSc}}}{V_{\mathrm{sSc}, \text { basket }}}\right)^{3} \text {, } \\
& x 1_{\mathrm{d} 3}=\frac{\mathrm{kd}_{\mathrm{C}-3} m_{\mathrm{C}-\mathrm{L}}^{0.75} T_{\mathrm{ISc}} C_{\mathrm{p}, \mathrm{SSc}} \frac{T_{\mathrm{air}}}{T_{\mathrm{melt}, \mathrm{SSc}}}}{\lambda_{\mathrm{C}}+C_{\mathrm{p}, \mathrm{C}}\left(T_{\text {melt }, \mathrm{sSc}}-T_{\mathrm{air}}\right)} \\
& x 1_{\mathrm{d} 4}=-x 1 \text { coal }_{\mathrm{d} 1}-\dot{m}_{\mathrm{comb}} \frac{9 M_{\mathrm{C}}}{M_{\mathrm{C}_{9} \mathrm{H}_{20}}}, \\
& x 1_{\mathrm{d} 5}=-K_{\mathrm{sSc}-\mathrm{ISc}}^{4} \mathrm{kd}_{\mathrm{C}-5} m_{\mathrm{C}-\mathrm{L}}^{0.75} c_{\mathrm{O}_{2}-\text { gas }}^{0.5},
\end{aligned}
$$

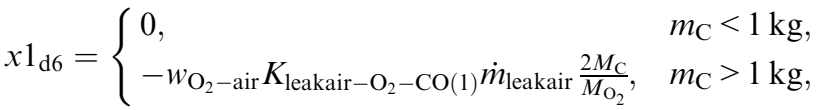

$$
\begin{aligned}
& x 1_{\mathrm{d} 7}=-r_{(\mathrm{s})} V_{(\mathrm{s})} M_{\mathrm{C}} \mathrm{kd}_{\mathrm{gas}-(\mathrm{s})}, \\
& \dot{m}_{\mathrm{C}-\mathrm{L}}=\sum_{j=1}^{7} x 1_{\mathrm{dj}} \text {. }
\end{aligned}
$$

The equation for the variable $x 1_{\mathrm{d} 2}$ is an empirical equation, which was developed during the parameterization of the adapted model using the available operating data. $\mathrm{kd}_{\mathrm{C}-\mathrm{L}}$ is the constant decarburization velocity and $m_{\mathrm{ISl}}$ is the total slag mass. The second summand $\left(0.6 x 1_{\mathrm{d} 1}\right)$ represents a direct reaction of injected $\mathrm{C}$ with $\mathrm{FeO}$. $V_{\mathrm{sSc}}$ is the actual bulk volume of the $\mathrm{sSc}$ and $V_{\mathrm{sSc} \text {,basket }}$ is the initial charged volume of sSc. The factor causes the chemical reaction in the simulation to start with increasing molten mass. If the furnace is full of scrap, the injected $\mathrm{C}$ does not reach the melt surface.

The equation for $x 1_{\mathrm{d} 3}$ is also an empirical equation, which resulted from the adaptation of Logar's equation during parameterization. The equation is dependent on the constant dissolving velocity $\mathrm{kd}_{\mathrm{C}-3}$, the temperatures of the melt $T_{1 \mathrm{Sc}}$, of the ambient air $T_{\text {air }}$ and the scrap's liquidus temperature $T_{\text {melt,sSc }}$, the heat capacities of $\mathrm{C}$ 
$C_{\mathrm{p}, \mathrm{C}}$ and the melt $C_{\mathrm{p}, \mathrm{ISc}}$, and the latent heat of fusion of $\mathrm{C} \lambda_{\mathrm{C}}$.

The combustible material consists of nonane and is denoted by $\dot{m}_{\text {comb }}$.

$\mathrm{kd}_{\mathrm{C}-5}$ is the constant $\mathrm{C}$ oxidation velocity. $K_{\mathrm{sSc}-\mathrm{ISc}}$ is the exposure coefficient of the liquid bath, because the reactionary surface of the melt decreases with increasing $\mathrm{sSc}$ volume. $c_{\mathrm{O}_{2}-\text { gas }}$ is the concentration of oxygen in the gas phase.

$w_{\mathrm{O}_{2} \text {-air }}$ is the mass fraction of $\mathrm{O}_{2}$ in the ambient air, which is sucked in as leak air $\dot{m}_{\text {leakair }}$ through the slag door and other gaps. $K_{\text {leakair- } \mathrm{O}_{2}-\mathrm{CO}(1)}$ is the fraction of leak air available for direct $\mathrm{C}$ combustion to $\mathrm{CO}$. The equation is divided into two cases, because otherwise the simulation would lead to negative masses as calculation results.

The calculations of $x 1_{\mathrm{d} 5}$ and $x 1_{\mathrm{d} 6}$ are based on the empirical reaction kinetic approach according to Eq. [12] for the reaction given by Eq. [13]:

$$
\begin{gathered}
-\frac{\mathrm{d}\left[c_{\mathrm{A}}\right]}{\mathrm{d} t}=k\left[c_{\mathrm{A}}\right]^{v_{\mathrm{A}}}\left[c_{\mathrm{B}}\right]^{v_{\mathrm{B}}}, \\
\left|v_{\mathrm{A}}\right| A+\left|v_{\mathrm{B}}\right| B \rightarrow\left|v_{\mathrm{C}}\right| C+\left|v_{\mathrm{D}}\right| D,
\end{gathered}
$$

where $A$ and $B$ are reactants with the concentration $c_{\mathrm{A}}$ or $c_{\mathrm{B}}$. The stoichiometric coefficients are signified with $v$, while $k$ is the corresponding reaction rate.

The calculation of the molar reaction rate $r_{(\mathrm{s})}$ in $x 1_{\mathrm{d} 7}$ follows Eqs. [14] and [15]. The database for $K_{\mathrm{c}}$ is evaluated for the assumed average temperature between the gas phase and the $1 \mathrm{Sc}$. The reaction volume $V_{(\mathrm{s})}$ is determined for each equilibrium reaction $\xi$ by Eq. [16] as a fraction of the total gas volume $V_{\text {gas }}$.

$$
\begin{gathered}
K_{\mathrm{c}-(\mathrm{s})}=f\left(\frac{T_{\mathrm{gas}}+T_{\mathrm{lSc}}}{2}\right), \\
r_{(\mathrm{s})}=K_{\mathrm{c}-(\mathrm{s})} c_{\mathrm{H}_{2} \mathrm{O}}^{-1}-c_{\mathrm{CO}} c_{\mathrm{H}_{2}}, \\
V_{(\xi)}=x_{(\xi)} V_{\text {gas }} .
\end{gathered}
$$

Only in case of a negative relative furnace pressure $p_{\mathrm{r}}$, the total mass flow of leak air enters the furnace. This is determined by Eq. [17] with $K_{\mathrm{PR}}$ representing a constant defining the ratio between mass flow and pressure:

$$
\dot{m}_{\text {leakair }}= \begin{cases}0, & p_{\mathrm{r}}>0, \\ K_{\mathrm{PR}} p_{\mathrm{r}}, & p_{\mathrm{r}}<0 .\end{cases}
$$

The rate of change of $\mathrm{C}$ from coal $\dot{m}_{\text {coal }}$ is determined by the following mechanisms: $\mathrm{C}$ is charged with coal within the scrap baskets. The reactive mass flow of $\mathrm{C}$ $\left(x 1\right.$ coal $\left._{\mathrm{d} 1}\right)$ is transferred from $m_{\text {coal }}$ to $m_{\mathrm{C}-\mathrm{L}}$ for decarburization, dissolving, and combustion. Analogous to $x 1_{\mathrm{d} 5}$ and $x 1_{\mathrm{d} 6}$, the amount of $\mathrm{C}$ from coal decreases due to the combustion of $\mathrm{C}$ to $\mathrm{CO}$ with the oxygen from the gas phase $\left(x\right.$ coal $\left._{\mathrm{d} 2}\right)$ and from the leak air $\left(x \operatorname{coal}_{\mathrm{d} 3}\right)$. C is taking part in the Boudouard reaction Eq. [3r] $\left(x \operatorname{coal}_{\mathrm{d} 4}\right)$. The mass change $\dot{m}_{\text {coal }}$ is given by Eq. [18]:

$$
\begin{aligned}
& x 1 \text { coal }_{\mathrm{d} 1}=-\mathrm{kd}_{\mathrm{C}-4} m_{\text {coal }}^{0.75} \sqrt{1-\frac{V_{\mathrm{sSc}}}{V_{\mathrm{SSc}, \text { basket }}}}, \\
& x 1 \text { coal }_{\mathrm{d} 2}=-\mathrm{kd}_{\mathrm{C}-6} m_{\text {coal }}^{0.75} c_{\mathrm{O}_{2} \text {-gas }}^{0.5}, \\
& x \text { coal }_{\mathrm{d} 3}= \begin{cases}0, & m_{\text {coal }}<1 \mathrm{~kg}, \\
-w_{\text {air }-\mathrm{O}_{2}} K_{\text {leakair }-\mathrm{O}_{2}-\mathrm{CO}(2)} \dot{m}_{\text {leakair }} \frac{2 M_{\mathrm{C}}}{M_{\mathrm{O}_{2}},} & m_{\text {coal }}>1 \mathrm{~kg},\end{cases} \\
& x 1_{\text {coal }} 1_{\mathrm{d} 4}=-r_{(\mathrm{r})} V_{(\mathrm{r})} M_{\mathrm{C}} \mathrm{kd}_{\text {gas }-(\mathrm{r})} \text {, } \\
& \dot{m}_{\text {coal }}=\sum_{j=1}^{4} x 1_{\text {coal }} \text { dj. }
\end{aligned}
$$

$\mathrm{kd}_{\mathrm{C}-4}$ and $\mathrm{kd}_{\mathrm{C}-6}$ represent the coal reactivity coefficients. The equations for $x 1_{\text {coal }} l_{\mathrm{d} 1}$ and $x 1_{\text {coal }}$ are developed empirical equations, which were validated by means of parametrization. The calculation of $r_{(\mathrm{r})}$ follows Eqs. [19] and [20], whereby the database for $K_{\mathrm{c}}$ is evaluated for the assumed average temperature.

$$
\begin{gathered}
K_{\mathrm{c}-(\mathrm{r})}=f\left(\frac{T_{\mathrm{gas}}+T_{1 \mathrm{Sc}}}{2}\right), \\
r_{(\mathrm{r})}=K_{\mathrm{c}-(\mathrm{r})} c_{\mathrm{CO}_{2}}^{-1}-c_{\mathrm{CO}}^{2} .
\end{gathered}
$$

The rate of change of dissolved $\mathrm{C}$ in the liquid melt $\left(\dot{m}_{\mathrm{C}-\mathrm{D}}\right)$ is determined according to Logar's description with a few enhancements and is given by Eq. [21]:

$$
\begin{aligned}
x 2_{\mathrm{d} 1} & =-\mathrm{kd}_{\mathrm{C}-\mathrm{D}}\left(X_{\mathrm{C}}-X_{\mathrm{C}}^{\mathrm{eq}}\right), \\
x 2_{\mathrm{d} 2} & =-\mathrm{kd}_{\mathrm{C}-1}\left(X_{\mathrm{C}}-X_{\mathrm{C}}^{\mathrm{eq}}\right) \dot{m}_{\mathrm{O}_{2}, \text { lance }} K_{\mathrm{O}_{2}-\mathrm{CO}} \frac{2 M_{\mathrm{C}}}{M_{\mathrm{O}_{2}}}, \\
x 2_{\mathrm{d} 3} & =-x 1_{\mathrm{d} 3}, \\
x 2_{\mathrm{d} 4} & =-\mathrm{kd}_{\mathrm{Mn}-1}\left(X_{\mathrm{MnO}}-X_{\mathrm{MnO}-1}^{\mathrm{eq}}\right) \frac{M_{\mathrm{C}}}{M_{\mathrm{MnO}}}, \\
x 2_{\mathrm{d} 5} & =-\mathrm{kd}_{\mathrm{C}-2}\left(X_{\mathrm{C}}-X_{\mathrm{C}}^{\mathrm{eq}}\right) \dot{m}_{\mathrm{O}_{2}-\text { lance }} K_{\mathrm{O}_{2}-\mathrm{CO}_{2}} \frac{2 M_{\mathrm{C}}}{M_{\mathrm{O}_{2}}}, \\
\dot{m}_{\mathrm{C}-\mathrm{D}} & =\sum_{j=1}^{5} x 2_{\mathrm{dj}},
\end{aligned}
$$

where $X_{i}$ and $X_{i}^{\mathrm{eq}}$ are the molar fractions and equilibrium molar fractions, respectively, $\mathrm{kd}_{\mathrm{C}-\mathrm{D}}$ is the $\mathrm{FeO}$ decarburization rate, $\mathrm{kd}_{\mathrm{C}-1}$ and $\mathrm{kd}_{\mathrm{C}-2}$ are the oxidation rates of $\mathrm{C}$ to $\mathrm{CO}$ and $\mathrm{CO}_{2}$, respectively, $\mathrm{kd}_{\mathrm{Mn}-1}$ is the $\mathrm{MnO}$ decarburization rate, and $K_{\mathrm{O}_{2}-\mathrm{CO}}$ and $K_{\mathrm{O}_{2}-\mathrm{CO}_{2}}$ are representing the fractions of the lanced oxygen used for direct oxidization. The two change rates $\dot{m}_{\mathrm{C}-\mathrm{L}}$ and $\dot{m}_{\mathrm{C}-\mathrm{D}}$ can be further improved by the solution presented by Fathi et al. ${ }^{[5]}$ All other rates of change for the components of the steel and slag zone are not changed and are implemented according to Logar et al $^{[3]}$

\section{Rate of change of carbon monoxide $(\mathrm{CO})$}

The rate of change of carbon monoxide in the gas phase $\left(\dot{m}_{\mathrm{CO}}\right)$ is implemented by nine mechanisms: $\mathrm{CO}$ is extracted with the off-gas $\left(x 9_{\mathrm{d} 1}\right)$ and through openings $\left(x 9_{\mathrm{d} 4}\right)$. CO is produced during the incomplete oxidation of $\mathrm{C}$ from coal, injected carbon $\left(x 9_{\mathrm{d} 2}\right)$, and $\mathrm{CH}_{4}\left(x 9_{\mathrm{d} 8}\right)$. Furthermore, sources are electrode oxidation and the 
oxidation of coal $\left(x 9_{\mathrm{d} 6}\right)$. CO is consumed by the $\mathrm{CO}$ post-combustion $\left(x 9_{\mathrm{d} 3}\right)$ and changed due to the equilibrium reactions of the homogeneous water-gas shift reaction $\left(x 9_{\mathrm{d} 5}\right)$, the Boudouard reaction $\left(x 9_{\mathrm{d} 7}\right)$, and the heterogeneous water-gas reaction $\left(x 9_{\mathrm{d} 9}\right)$. The rate of change of $\mathrm{CO}$ is obtained by Eq. [22]:

$$
\begin{aligned}
x 9_{\mathrm{d} 1}= & -\frac{h_{\mathrm{d}} u_{1} m_{\mathrm{CO}}}{\left(k_{\mathrm{u}} u_{2}+h_{\mathrm{d}}\right) m_{\mathrm{gas}}}, \\
x 9_{\mathrm{d} 2} & =-\left(x 1_{\mathrm{d} 2}+x 1_{\mathrm{d} 5}+x 1_{\mathrm{d} 6}+x 1 \operatorname{coal}_{\mathrm{d} 2}+x 1 \operatorname{coal}_{\mathrm{d} 3}\right. \\
& \left.+x 2_{\mathrm{d} 1}+x 2_{\mathrm{d} 2}+x 2_{\mathrm{d} 4}\right) \frac{M_{\mathrm{CO}}}{M_{\mathrm{C}}},
\end{aligned}
$$

$x 9_{\mathrm{d} 3}=-\mathrm{kd}_{\mathrm{CO}-1} m_{\mathrm{CO}} c_{\mathrm{O}_{2}-\text { gas }}^{0.5}-\dot{m}_{\mathrm{O}_{2}-\text { post }} K_{\mathrm{O}_{2}-\text { post }-\mathrm{CO}} \frac{2 M_{\mathrm{CO}}}{M_{\mathrm{O}_{2}}}$,

$x 9_{\mathrm{d} 4}= \begin{cases}-K_{\mathrm{PR}} p_{\mathrm{r}} \frac{m_{\mathrm{CO}}}{m_{\mathrm{gas}},} & p_{\mathrm{r}}>0, \\ 0, & p_{\mathrm{r}}<0,\end{cases}$

$x 9_{\mathrm{d} 5}=r_{(\mathrm{q})} V_{(\mathrm{q})} M_{\mathrm{CO}} \mathrm{kd}_{\mathrm{gas}-(\mathrm{q})}$,

$x 9_{\mathrm{d} 6}=-\dot{m}_{\mathrm{el}} \frac{M_{\mathrm{CO}}}{M_{\mathrm{C}}}$,

$x 9_{\mathrm{d} 7}=-x \operatorname{coal}_{\mathrm{d} 4} \frac{2 M_{\mathrm{CO}}}{M_{\mathrm{C}}}$,

$x 9_{\mathrm{d} 8}=-\left(x 15_{\mathrm{d} 5}+x 15_{\mathrm{d} 8}\right) \frac{M_{\mathrm{CO}}}{M_{\mathrm{CH}_{4}}}$,

$x 9_{\mathrm{d} 9}=-x 1_{\mathrm{d} 7} \frac{M_{\mathrm{CO}}}{M_{\mathrm{C}}}$,

$\dot{m}_{\mathrm{CO}}=\sum_{j=1}^{9} x 9_{\mathrm{dj}}$.

The equation for $x 9_{\mathrm{d} 1}$ is equal to Logar et al.' $\mathrm{s}^{[3]}$ implementation with $h_{\mathrm{d}}$ being the characteristic dimension of the duct area at the slip gap, $u_{1}$ is the off-gas mass flow, $k_{\mathrm{u}}$ is a dimensionless constant and set to the same value as proposed by Bekker et al., ${ }^{[17]}$ and $u_{2}$ is the slip gap width.

$\mathrm{kd}_{\mathrm{CO}-1}$ is the reaction velocity of the $\mathrm{CO}$ post-combustion. In order to promote this reaction in the EAF, an oxygen mass flow $\dot{m}_{\mathrm{O}_{2}-\text { post }}$ is injected via lance. Further-

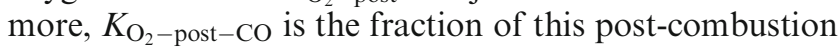
$\mathrm{O}_{2}$ mass flow used for $\mathrm{CO}$ post-combustion.

The outflow of gas through openings is modeled analogously to the inflow of leak air in Eq. [16]. If an overpressure prevails in the vessel, furnace gas is discharged.

The reaction rate $r_{(\mathrm{q})}$ of $x 9_{\mathrm{d} 5}$ is determined with the equilibrium constant $K_{\text {c-(q) }}$ by Eqs. [23] and [24]:

$$
\begin{gathered}
K_{\mathrm{c}-(\mathrm{q})}=f\left(T_{\text {gas }}\right), \\
r_{(\mathrm{q})}=K_{\mathrm{c}-(\mathrm{q})} c_{\mathrm{CO}}^{-1} c_{\mathrm{H}_{2} \mathrm{O}}^{-1}-c_{\mathrm{CO}_{2}} c_{\mathrm{H}_{2}} .
\end{gathered}
$$

$\mathrm{kd}_{\text {gas-(q) }}$ is the reaction velocity of the homogeneous water-gas shift reaction and is-like all other reaction velocities kd-given in Table II in Appendix.

The graphite electrode oxidizes during the EAF operation. A minor mass of $\mathrm{C}\left(\dot{m}_{\mathrm{el}}\right)$ releases, which can react with the gas phase. The corresponding calculation is described in Logar et al.$^{[3]}$
4. Rate of change of carbon dioxide $\left(\mathrm{CO}_{2}\right)$

The rate of change of carbon dioxide in the gas phase $\left(\dot{m}_{\mathrm{CO}_{2}}\right)$ is determined by the following mechanisms: $\mathrm{CO}_{2}$ is extracted with the off-gas $\left(x 10_{\mathrm{d} 1}\right)$ and flows out through openings $\left(x 10_{\mathrm{d} 7}\right) \cdot \mathrm{CO}_{2}$ arises from $\mathrm{CO}$ post-combustion $\left(x 10_{\mathrm{d} 2}\right), \mathrm{CH}_{4}$ combustion $\left(x 10_{\mathrm{d} 4}\right.$ and $\left.x 10_{\mathrm{d} 6}\right)$, and from dissolved $\mathrm{C}$ oxidation $\left(x 10_{\mathrm{d} 8}\right) \cdot \mathrm{CO}_{2}$ takes part in the equilibrium reactions of the homogeneous water-gas shift reaction $\left(x 10_{\mathrm{d} 3}\right)$ and the Boudouard reaction $\left(x 10_{\mathrm{d} 5}\right)$. The rate of change of $\mathrm{CO}_{2}$ is obtained by Eq. [25]:

$$
\begin{aligned}
& x 10_{\mathrm{d} 1}=-\frac{h_{\mathrm{d}} u_{1} m_{\mathrm{CO}_{2}}}{\left(k_{\mathrm{u}} u_{2}+h_{\mathrm{d}}\right) m_{\mathrm{gas}}}, \\
& x 10_{\mathrm{d} 2}=-\frac{M_{\mathrm{CO}_{2}}}{M_{\mathrm{CO}}} x 9_{\mathrm{d} 3}, \\
& x 10_{\mathrm{d} 3}=-x 9_{\mathrm{d} 5} \frac{M_{\mathrm{CO}_{2}}}{M_{\mathrm{CO}}}, \\
& x 10_{\mathrm{d} 4}=-x 15_{\mathrm{d} 4} \frac{M_{\mathrm{CO}_{2}}}{M_{\mathrm{CH}_{4}}}, \\
& x 10_{\mathrm{d} 5}=x 1 \operatorname{coa} 1_{\mathrm{d} 4} \frac{M_{\mathrm{CO}_{2}}}{M_{\mathrm{C}}}, \\
& x 10_{\mathrm{d} 6}=-x 15_{\mathrm{d} 6} \frac{M_{\mathrm{CO}_{2}}}{M_{\mathrm{CH}_{4}}}, \\
& x 10_{\mathrm{d} 7}= \begin{cases}-K_{\mathrm{PR}} p_{\mathrm{r}} \frac{m_{\mathrm{CO}_{2}}}{m_{\mathrm{gas}}}, & p_{\mathrm{r}}>0, \\
0, & M_{\mathrm{r}}<0,\end{cases} \\
& x 10_{\mathrm{d} 8}=-x 2_{\mathrm{d} 5 \frac{M_{\mathrm{CO}_{2}}}{M_{\mathrm{C}}},} \\
& \dot{m}_{\mathrm{CO}_{2}}=\sum_{j=1}^{8} x 10_{\mathrm{dj}} .
\end{aligned}
$$

\section{Rate of change of nitrogen $\left(N_{2}\right)$}

The rate of change of nitrogen $\left(\dot{m}_{\mathrm{N}_{2}}\right)$ is determined by the extraction with the off-gas $\left(x 11_{\mathrm{d} 1}\right)$ and the outflow through openings $\left(x 11_{\mathrm{d} 2}\right.$ for $\left.p_{\mathrm{r}}>0\right)$. For a negative relative pressure, $\mathrm{N}_{2}$ is sucked in with the leak air $\left(x 11_{\mathrm{d} 2}\right.$ for $\left.p_{\mathrm{r}}<0\right)$. Furthermore, $\mathrm{N}_{2}$ is injected together with the injected $\mathrm{O}_{2}, \mathrm{CH}_{4}$, and $\mathrm{C}$ mass flows $\left(x 11_{\mathrm{d} 3}\right)$. Compared to Logar et al., ${ }^{[3]}$ the rate of change of $\mathrm{N}_{2}$ is supplemented by $x 11_{\mathrm{d} 3}$ and determined by Eq. [26]:

$$
\begin{aligned}
x 11_{\mathrm{d} 1}= & -\frac{h_{\mathrm{d}} u_{1} m_{\mathrm{N}_{2}}}{\left(k_{\mathrm{u}} u_{2}+h_{\mathrm{d}}\right) m_{\mathrm{gas}}}, \\
x 11_{\mathrm{d} 2}= & \begin{cases}-K_{\mathrm{PR}} p_{\mathrm{r}} \frac{m_{\mathrm{CO}}}{m_{\mathrm{gas}}}, & p_{\mathrm{r}}>0, \\
w_{\mathrm{N}_{2}-\text { air }} \dot{m}_{\text {leakair }}, & p_{\mathrm{r}}<0,\end{cases} \\
x 11_{\mathrm{d} 3}= & \dot{m}_{\mathrm{CH}_{4}-\text { inj } \frac{w_{\mathrm{N}_{2}-\text { in-natgas }}}{w_{\mathrm{CH}_{4}-\text { in }- \text { natgas }}}} \\
& +\left(\dot{m}_{\mathrm{O}_{2}-\text { lance }}+\dot{m}_{\mathrm{O}_{2}-\text { post }}+\dot{m}_{\mathrm{O}_{2}-\mathrm{CH}_{4}-\text { inj }}\right) \\
& \frac{w_{\mathrm{N}_{2}-\text { in-oxygen }}}{w_{\mathrm{O}_{2}-\text { in-oxygen }}}, \\
\dot{m}_{\mathrm{N}_{2}=}= & \sum_{j=1}^{3} x 11_{\mathrm{dj}},
\end{aligned}
$$

where all $w_{i}$ are the mass fractions of the following mass flows. $w_{\mathrm{N}_{2}-\text { air }}$ is the mass fraction of $\mathrm{N}_{2}$ in the leak air, 
$w_{\mathrm{N}_{2}-\text { in-natgas }}$ and $w_{\mathrm{CH}_{4}-\mathrm{in} \text {-natgas }}$ are the mass fractions of $\mathrm{N}_{2}$ and $\mathrm{CH}_{4}$ in the injected natural gas, respectively, $w_{\mathrm{N}_{2} \text {-in-oxygen }}$ and $w_{\mathrm{O}_{2}-\text { in-oxygen }}$ are the mass fractions of $\mathrm{N}_{2}$ and $\mathrm{O}_{2}$ in the injected oxygen mass flows. Therefore, the considered $\mathrm{O}_{2}$ is injected via lance for the reduction of $\mathrm{Fe}\left(\dot{m}_{\mathrm{O}_{2} \text {-lance }}\right)$, via tuyere for post-combustion $\left(\dot{m}_{\mathrm{O}_{2}-\text { post }}\right)$, and via the burner system $\left(\dot{m}_{\mathrm{O}_{2}-\mathrm{CH}_{4}-\mathrm{inj}}\right)$.

\section{Rate of change of oxygen $\left(\mathrm{O}_{2}\right)$}

The rate of change of oxygen in the gas zone $\left(\dot{m}_{\mathrm{O}_{2}}\right)$ is determined by the following mechanisms: $\mathrm{O}_{2}$ is extracted with the off-gas $\left(x 12_{\mathrm{d} 1}\right)$ and flows out through openings in the EAF vessel $\left(x 12_{\mathrm{d} 7}\right.$ for $\left.p_{\mathrm{r}}>0\right)$. For a negative relative pressure, $\mathrm{O}_{2}$ is sucked in with leak air $\left(x 12_{\mathrm{d} 7}\right.$ for $\left.p_{\mathrm{r}}<0\right)$. Further, a residual $\mathrm{O}_{2}$ mass flow remains of all $\mathrm{O}_{2}$ lanced into the gas phase $\left(x 12_{\mathrm{d} 2}\right)$ due to incomplete oxidation reactions, e.g., during the oxidation of dissolved $\mathrm{C}$ in the liquid melt $\left(x 2_{\mathrm{d} 2}\right.$ and $\left.x 2_{\mathrm{d} 5}\right), \mathrm{Si}\left(x 3_{\mathrm{d} 2}\right), \mathrm{Cr}\left(x 5_{\mathrm{d} 2}\right), \mathrm{P}\left(x 6_{\mathrm{d} 2}\right)$, and $\mathrm{Fe}\left(x 7_{\mathrm{d} 3}\right) \cdot \mathrm{O}_{2}$ is injected with the natural gas though the burner system into the EAF $\left(\dot{m}_{\mathrm{O}_{2}-\mathrm{CH}_{4}-\mathrm{inj}}\right)$, which reacts with $\mathrm{CH}_{4}$ in different burner zones $\left(x 15_{d i}\right)$ and leaves a residual $\mathrm{O}_{2}$ mass flow $\left(x 12_{\mathrm{d} 3}\right) \cdot \mathrm{O}_{2}$ is injected $\left(\dot{m}_{\mathrm{O}_{2}-\text { post }}\right)$ for $\mathrm{CO}$ post-combustion $\left(x 9_{\mathrm{d} 3}\right)$ and leaves a residual mass flow $\left(x 12_{\mathrm{d} 4}\right)$. The oxidation of the electrodes consumes $\mathrm{O}_{2}(x 12 \mathrm{~d} 5)$ as well as the combustion of coal and $\mathrm{C}$ in the EAF $\left(x 12_{\mathrm{d} 6}\right)$. In addition, the post-combustion of $\mathrm{CH}_{4}\left(x 12_{\mathrm{d} 8}\right)$ also uses up $\mathrm{O}_{2}$. The post-combustion of $\mathrm{H}_{2}$ $\left(x 13_{\mathrm{d} 4}\right)$ is combined with the dissociation of $\mathrm{H}_{2} \mathrm{O}\left(x 14_{\mathrm{d} 5}\right)$ in the change of $\mathrm{O}_{2}\left(x 12_{\mathrm{d} 9}\right)$. The total rate of change of $\mathrm{O}_{2}$ is determined with Eq. [27]:

$$
\begin{aligned}
x 12_{\mathrm{d} 1} & =-\frac{h_{\mathrm{d}} u_{1} m_{\mathrm{O}_{2}}}{\left(k_{\mathrm{u}} u_{2}+h_{\mathrm{d}}\right) m_{\mathrm{gas}}}, \\
x 12_{\mathrm{d} 2} & =\dot{m}_{\mathrm{O}_{2}-\text { lance }}+x 2_{\mathrm{d} 2} \frac{M_{\mathrm{O}_{2}}}{2 M_{\mathrm{C}}}+x 2_{\mathrm{d} 5} \frac{M_{\mathrm{O}_{2}}}{M_{\mathrm{C}}}+x 3_{\mathrm{d} 2} \frac{M_{\mathrm{O}_{2}}}{M_{\mathrm{Si}}} \\
& +x 5_{\mathrm{d} 2} \frac{3 M_{\mathrm{O}_{2}}}{4 M_{\mathrm{Cr}}}+x 6_{\mathrm{d} 2} \frac{5 M_{\mathrm{O}_{2}}}{4 M_{\mathrm{P}}}-x 7_{\mathrm{d} 3} \frac{M_{\mathrm{O}_{2}}}{2 M_{\mathrm{FeO}}}, \\
x 12_{\mathrm{d} 3} & =\dot{m}_{\mathrm{O}_{2}-\mathrm{CH}_{4}-\mathrm{inj}}+x 15_{\mathrm{d} 4} \frac{2 M_{\mathrm{O}_{2}}}{M_{\mathrm{CH}_{4}}}+x 15_{\mathrm{d} 5} \frac{3 M_{\mathrm{O}_{2}}}{2 M_{\mathrm{CH}_{4}}}+x 15_{\mathrm{d} 6} \frac{M_{\mathrm{O}_{2}}}{M_{\mathrm{CH}_{4}}}, \\
x 12_{\mathrm{d} 4} & =\dot{m}_{\mathrm{O}_{2}-\text { post }}+x 9_{\mathrm{d} 3} \frac{M_{\mathrm{O}_{2}}}{2 M_{\mathrm{CO}}}, \\
x 12_{\mathrm{d} 5} & =\dot{m}_{\mathrm{el}} \frac{M_{\mathrm{O}_{2}}}{2 M_{\mathrm{C}}}, \\
x 12_{\mathrm{d} 6} & =\left(x 1_{\mathrm{d} 5}+x 1_{\mathrm{d} 6}+x 1 \mathrm{coal} l_{\mathrm{d} 2}+x 1 \mathrm{coal} 1_{\mathrm{d} 3}\right) \frac{M_{\mathrm{O}_{2}}}{2 M_{\mathrm{C}}}, \\
x 12_{\mathrm{d} 7} & = \begin{cases}-K_{\mathrm{PR}} p_{\mathrm{r}} \frac{m_{\mathrm{O}_{2}}}{m_{\mathrm{gas}}}, \quad p_{\mathrm{r}}>0, \\
w_{\mathrm{air}-\mathrm{O}_{2}} \dot{m}_{\text {leakair }}, \quad p_{\mathrm{r}}<0,\end{cases} \\
x 12_{\mathrm{d} 8} & =x 15_{\mathrm{d} 8} \frac{3 M_{\mathrm{O}_{2}}}{2 M_{\mathrm{CH}_{4}}}, \\
x 12_{\mathrm{d} 9} & =x 13_{\mathrm{d} 4} \frac{M_{\mathrm{O}_{2}}}{2 M_{\mathrm{H}_{2}}}-x 14_{\mathrm{d} 5} \frac{M_{\mathrm{O}_{2}}}{2 M_{\mathrm{H}_{2} \mathrm{O}}}, \\
\dot{m} \mathrm{O}_{2} & =\sum_{j=1}^{9} x 12_{\mathrm{dj}} .
\end{aligned}
$$

7. Rate of change of hydrogen $\left(\mathrm{H}_{2}\right)$

The rate of change of hydrogen in the gas zone $\left(\dot{m}_{\mathrm{H}_{2}}\right)$ is determined by the following mechanisms: $\mathrm{H}_{2}$ is extracted with the off-gas $\left(x 13_{\mathrm{d} 1}\right)$ and flows out through openings $\left(x 13_{\mathrm{d} 2}\right)$. There is an assumed $\mathrm{H}_{2}$ residual mass flow caused by an incomplete $\mathrm{CH}_{4}$ combustion from burners $\left(x 13_{\mathrm{d} 3}\right) . \mathrm{H}_{2}$ is produced during the dissociation of combustible materials $\left(x 13_{\mathrm{d} 7}\right)$ and $\mathrm{H}_{2}$ is consumed during post-combustion $\left(x 13_{\mathrm{d} 4}\right)$. Furthermore, $\mathrm{H}_{2}$ takes part in the equilibrium reactions of the heterogeneous $\left(x 13_{\mathrm{d} 5}\right)$ and homogeneous water-gas reactions $\left(x 13_{\mathrm{d} 6}\right)$. The rate of change is obtained by Eq. [28]:

$$
\begin{aligned}
x 13_{\mathrm{d} 1} & =-\frac{h_{\mathrm{d}} u_{1} m_{\mathrm{H}_{2}}}{\left(k_{\mathrm{u}} u_{2}+h_{\mathrm{d}}\right) m_{\mathrm{gas}}}, \\
x 13_{\mathrm{d} 2} & = \begin{cases}-K_{\mathrm{PR}} p_{\mathrm{r}} \frac{m_{\mathrm{H}_{2}}}{m_{\mathrm{gas}}}, & p_{\mathrm{r}}>0, \\
0, & p_{\mathrm{r}}<0,\end{cases} \\
x 13_{\mathrm{d} 3} & =-x 15_{\mathrm{d} 6 \frac{2 M_{\mathrm{H}_{2}}}{M_{\mathrm{CH}_{4}}},} \\
x 13_{\mathrm{d} 4} & =-\mathrm{kd}_{\mathrm{H}_{2}-\text { post }} m_{\mathrm{H}_{2}} c_{\mathrm{O}_{2}-\mathrm{gas}}^{0.5}, \\
x 13_{\mathrm{d} 5} & =-x 1_{\mathrm{d} 7 \frac{M_{\mathrm{H}_{2}}}{M_{\mathrm{C}}},}, \\
x 13_{\mathrm{d} 6} & =-x 9_{\mathrm{d} 5 \frac{M_{\mathrm{H}_{2}}}{M_{\mathrm{CO}}},} \\
x 13_{\mathrm{d} 7} & =-\dot{m}_{\mathrm{comb}} \frac{10 M_{\mathrm{H}_{2}}}{M_{\mathrm{C}_{9} \mathrm{H}_{20}}}, \\
\dot{m}_{\mathrm{H}_{2}} & =\sum_{j=1}^{7} x 13_{\mathrm{dj}},
\end{aligned}
$$

where $\mathrm{kd}_{\mathrm{H}_{2} \text {-post }}$ is the reaction rate constant of the $\mathrm{H}_{2}$ post-combustion.

\section{Rate of change of water vapor $\left(\mathrm{H}_{2} \mathrm{O}\right)$}

The rate of change of water vapor in the gas zone $\left(\dot{m}_{\mathrm{H}_{2} \mathrm{O}}\right)$ is determined by the following mechanisms: $\mathrm{H}_{2} \mathrm{O}$ is extracted with the off-gas $\left(x 14_{\mathrm{d} 1}\right)$ and flows out through openings $\left(x 14_{\mathrm{d} 2}\right)$ and enters the EAF via the electrode cooling $\left(x 14_{\mathrm{d} 3}\right)$. To decrease the electrode consumption, the graphite electrode is equipped with a water spray cooling system at its top. The water $\left(\dot{m}_{\text {water-in }}\right)$ flows down the electrode and evaporates, whereby a part of the steam is assumed to enter the EAF vessel. Furthermore, $\mathrm{H}_{2} \mathrm{O}$ is a product of the $\mathrm{CH}_{4}\left(x 14_{\mathrm{d} 4}\right.$ and $\left.x 14_{\mathrm{d} 6}\right)$ and $\mathrm{H}_{2}$ combustion $\left(x 14_{\mathrm{d} 7}\right) . \mathrm{H}_{2} \mathrm{O}$ takes part in the equilibrium reactions of the heterogeneous $\left(x 14_{\mathrm{d} 8}\right)$ and homogeneous water-gas reactions $\left(x 14_{\mathrm{d} 9}\right) . x 14_{\mathrm{d} 5}$ describes a simplified exponential approach for the dissociation of water, as the dissociation is encouraged by attendance of metal oxides. ${ }^{[18]}$ The rate of change is obtained by Eq. [29]:

$$
\begin{aligned}
& x 14_{\mathrm{d} 1}=-\frac{h_{\mathrm{d}} u_{1} m_{\mathrm{H}_{2} \mathrm{O}}}{\left(k_{\mathrm{u}} u_{2}+h_{\mathrm{d}}\right) m_{\mathrm{gas}}}, \\
& x 14_{\mathrm{d} 2}= \begin{cases}-K_{\mathrm{PR}} p_{\mathrm{r}} \frac{m_{\mathrm{H}_{2} \mathrm{O}}}{m_{\text {gas }}}, & p_{\mathrm{r}}>0, \\
0, & p_{\mathrm{r}}<0,\end{cases} \\
& x 14_{\mathrm{d} 3}=-\dot{m}_{\mathrm{water}-\mathrm{in},}, \\
& x 14_{\mathrm{d} 4}=-x 15_{\mathrm{d} 8} \frac{2 M_{\mathrm{H}_{2} \mathrm{O}}}{M_{\mathrm{CH}_{4}}},
\end{aligned}
$$




$$
\begin{aligned}
& x 14_{\mathrm{d} 5}=-\mathrm{kd}_{\mathrm{H}_{2} \mathrm{O}} \exp \left(\frac{m_{\mathrm{H}_{2} \mathrm{O}}}{5}\right) \\
& x 14_{\mathrm{d} 6}=-\left(x 15_{\mathrm{d} 4}+x 15_{\mathrm{d} 5}\right) \frac{2 M_{\mathrm{H}_{2} \mathrm{O}}}{M_{\mathrm{CH}_{4}}} \\
& x 14_{\mathrm{d} 7}=-x 13_{\mathrm{d} 4} \frac{M_{\mathrm{H}_{2} \mathrm{O}}}{M_{\mathrm{H}_{2}}} \\
& x 14_{\mathrm{d} 8}=x 1_{\mathrm{d} 7} \frac{M_{\mathrm{H}_{2} \mathrm{O}}}{M_{\mathrm{C}}} \\
& x 14_{\mathrm{d} 9}=-x 9_{\mathrm{d} 5} \frac{M_{\mathrm{H}_{2} \mathrm{O}}}{M_{\mathrm{CO}}} \\
& \dot{m}_{\mathrm{H}_{2} \mathrm{O}}=\sum_{j=1}^{9} x 14_{\mathrm{dj}} .
\end{aligned}
$$

\section{Rate of change of methane $\left(\mathrm{CH}_{4}\right)$}

The rate of change of methane in the gas zone $\left(\dot{m}_{\mathrm{CH}_{4}}\right)$ is determined by the following mechanisms: $\mathrm{CH}_{4}$ is extracted with the off-gas $\left(x 15_{\mathrm{d} 1}\right)$ and flows out through openings $\left(x 15_{\mathrm{d} 2}\right)$. Natural gas, which consists mainly of $\mathrm{CH}_{4}$, is injected through the burner system $\left(x 15_{\mathrm{d} 3}\right)$. The $\mathrm{CH}_{4}$ is assumed to react in three different ways $\left(x 15_{\mathrm{d} 4}\right.$, $x 15_{\mathrm{d} 5}$, and $\left.x 15_{\mathrm{d} 6}\right)$ and, finally, $\mathrm{CH}_{4}$ is post-combusted $\left(x 15_{\mathrm{d} 7}\right)$. The rate of change is obtained by Eq. [30]:

$$
\begin{aligned}
& x 15_{\mathrm{d} 1}=-\frac{h_{\mathrm{d}} u_{1} m_{\mathrm{CH}_{4}}}{\left(k_{\mathrm{u}} u_{2}+h_{\mathrm{d}}\right) m_{\mathrm{gas}}}, \\
& x 15_{\mathrm{d} 2}= \begin{cases}-K_{\mathrm{PR}} p_{\mathrm{r}} \frac{m_{\mathrm{CH}_{4}}}{m_{\mathrm{gas}}}, & p_{\mathrm{r}}>0, \\
0, & p_{\mathrm{r}}<0,\end{cases} \\
& x 15_{\mathrm{d} 3}=\dot{m}_{\mathrm{CH}_{4}-\mathrm{inj}},
\end{aligned}
$$

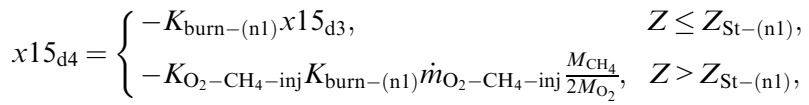

$$
\begin{aligned}
& x 15_{\mathrm{d} 5}= \begin{cases}-K_{\mathrm{burn}-(\mathrm{n} 2)} x 15_{\mathrm{d} 3}, & Z \leq Z_{\mathrm{St}-(\mathrm{n} 2)}, \\
-K_{\mathrm{O}_{2}-\mathrm{CH}_{4}-\mathrm{inj}} K_{\mathrm{burn}-(\mathrm{n} 2)} \dot{m}_{\mathrm{O}_{2}-\mathrm{CH}_{4}-i n j} \frac{2 M_{\mathrm{CH}_{4}}}{3 M_{\mathrm{O}_{2}}}, & Z>Z_{\mathrm{St}-(\mathrm{n} 2)},\end{cases}
\end{aligned}
$$

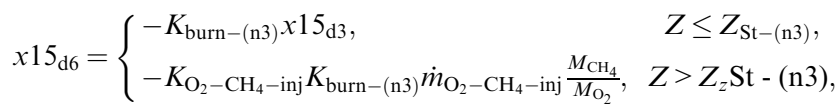

$$
\begin{aligned}
& x 15_{\mathrm{d} 7}=-\mathrm{kd}_{\mathrm{CH}_{4}-\text { post }} m_{\mathrm{CH}_{4}} c_{\mathrm{O}_{2}-\text { gas }}^{1.5} \text {, } \\
& \dot{m}_{\mathrm{CH}_{4}}=\sum_{j=1}^{7} x 15_{\mathrm{dj}} \text {, }
\end{aligned}
$$

where $\mathrm{kd}_{\mathrm{CH}_{4}-\text { post }}$ represents the reaction rate of $\mathrm{CH}_{4}$ post-combustion. It is assumed that there are three different reaction zones of the burner flame due to the non-premixed supply of $\mathrm{CH}_{4}$ and $\mathrm{O}_{2}$. Within the reaction volumes, the respective reactions of Eqs. [6n $],\left[6 n_{2}\right]$, and [6n 3 take place. Therefore, $K_{\text {burn-(n1), }} K_{\text {burn-(n2), }}$ and $K_{\text {burn-(n3) }}$ are the corresponding percentages of the reaction volumes.

The reaction rates are limited by the ratio of $\mathrm{O}_{2}$ to $\mathrm{CH}_{4}$. The stoichiometric mixture fraction $Z_{\text {St-(ni) }}$ according to Peters ${ }^{[19]}$ is compared with the actual mixture fraction $Z$ of the supplied gas mass flows, which is defined according to Eq. [31]:

$$
Z=\frac{\dot{m}_{\mathrm{CH}_{4}-\mathrm{inj}}}{\dot{m}_{\mathrm{CH}_{4}-\mathrm{in}}+\dot{m}_{\mathrm{O}_{2}-\mathrm{CH}_{4}-\mathrm{inj}}} .
$$

The stoichiometric mixing fraction $Z_{\text {St-(ni) }}$ is obtained in general by Eq. [32] and for the three reactions according to Eqs. [33] through [35]:

$$
\begin{gathered}
Z_{\mathrm{St}-(\mathrm{ni})}=\frac{v_{\mathrm{CH}_{4}, \mathrm{i}} M_{\mathrm{CH}_{4}}}{v_{\mathrm{CH}_{4}, \mathrm{i}} M_{\mathrm{CH}_{4}}+v_{\mathrm{O}_{2}, \mathrm{i}} M_{\mathrm{O}_{2}} \frac{w_{\mathrm{CH}_{4} \text {-in-natgas }}}{w_{\mathrm{O}_{2} \text {-in-oxygen }}}}, \\
Z_{\mathrm{St}-(\mathrm{n} 1)}=\frac{M_{\mathrm{CH}_{4}}}{M_{\mathrm{CH}_{4}}+2 M_{\mathrm{O}_{2}} \frac{w_{\mathrm{CH}_{4} \text {-in-natgas }}}{w_{\mathrm{O}_{2} \text {-in-oxygen }}}}, \\
Z_{\mathrm{St}-(\mathrm{n} 2)}=\frac{M_{\mathrm{CH}_{4}}}{M_{\mathrm{CH}_{4}}+\frac{3}{2} M_{\mathrm{O}_{2}} \frac{w_{\mathrm{CH}_{4} \text {-in-natgas }}}{w_{\mathrm{O}_{2} \text {-in-oxygen }}}}, \\
Z_{\mathrm{St}-(\mathrm{n} 3)}=\frac{M_{\mathrm{CH}_{4}}}{M_{\mathrm{CH}_{4}}+M_{\mathrm{O}_{2}} \frac{w_{\mathrm{CH}_{4} \text {-in-natgas }}}{w_{\mathrm{O}_{2} \text {-in-oxygen }}}} .
\end{gathered}
$$

For $Z \leq Z_{\mathrm{St}}$, the natural gas mass flow $x 15_{\mathrm{d} 3}$ is completely consumed and for $Z>Z_{\mathrm{St}}$ the reaction rate is limited by the available fraction of the burner oxygen. $K_{\mathrm{O}_{2}-\mathrm{CH}_{4}-\mathrm{inj}}$ is the fraction of the injected $\mathrm{O}_{2}$ mass flow available for direct $\mathrm{CH}_{4}$ combustion. This empirical factor is calculated according to the coverage of the burner nozzle openings by scrap (e.g., after scrap charging). In this case, only an insufficient mixing of the two gases $\mathrm{CH}_{4}$ and $\mathrm{O}_{2}$ is assumed, which leads to an incomplete reaction of $\mathrm{CH}_{4} \cdot \mathrm{K}_{\mathrm{O}_{2}-\mathrm{CH}_{4}-\text { inj }}$ is calculated with Eq. [36], which has been empirically derived based on the scrap meltdown progress in front of the burner nozzle:

$$
K_{\mathrm{O}_{2}-\mathrm{CH}_{4}-\mathrm{inj}}=1-0.75\left(\frac{m_{\mathrm{sSc}}}{m_{\mathrm{sSc}, \text { basket }}}\right)^{2},
$$

where $m_{\mathrm{sSc} \text {,basket }}$ represents the mass of scrap charged into the EAF.

Together with the scrap, combustible materials like grease, oils, and paints enter into the EAF. These materials are taken into account as a mass of nonane $\left(\mathrm{C}_{9} \mathrm{H}_{20}\right)$ and it is assumed that $\mathrm{C}_{9} \mathrm{H}_{20}$ dissociates before further reactions take place. The dissociation follows the empirical approach in Eq. [37], which has been adopted from Logar et $a l^{[3]}$ and adjusted to improve the agreement of simulation and measurement results.

$$
\dot{m}_{\text {comb }}=-\mathrm{kd}_{\text {comb }} m_{\text {comb }}^{0.75}\left(1.1-\frac{V_{\text {sSc }}}{V_{\text {sSc,basket }}}\right)^{2} .
$$

\section{Reaction Enthalpies}

Chemical reactions lead to a conversion of energy. Exothermic or endothermic reactions are releasing or consuming energy to the corresponding zone or phase in which the reaction takes place. The enthalpy of the reactions is therefore computed according to Logar et al ${ }^{[3]}$ by Eq. [39]:

$$
\begin{aligned}
\Delta H_{T}^{0}= & \sum \Delta H_{298}^{0}(\text { products })-\sum \Delta H_{298}^{0}(\text { reactants }) \\
& +\int_{298 \mathrm{~K}}^{T}\left[\sum C_{\mathrm{p}}(\text { products })-\sum C_{\mathrm{p}}(\text { reactants })\right] \mathrm{d} T,
\end{aligned}
$$




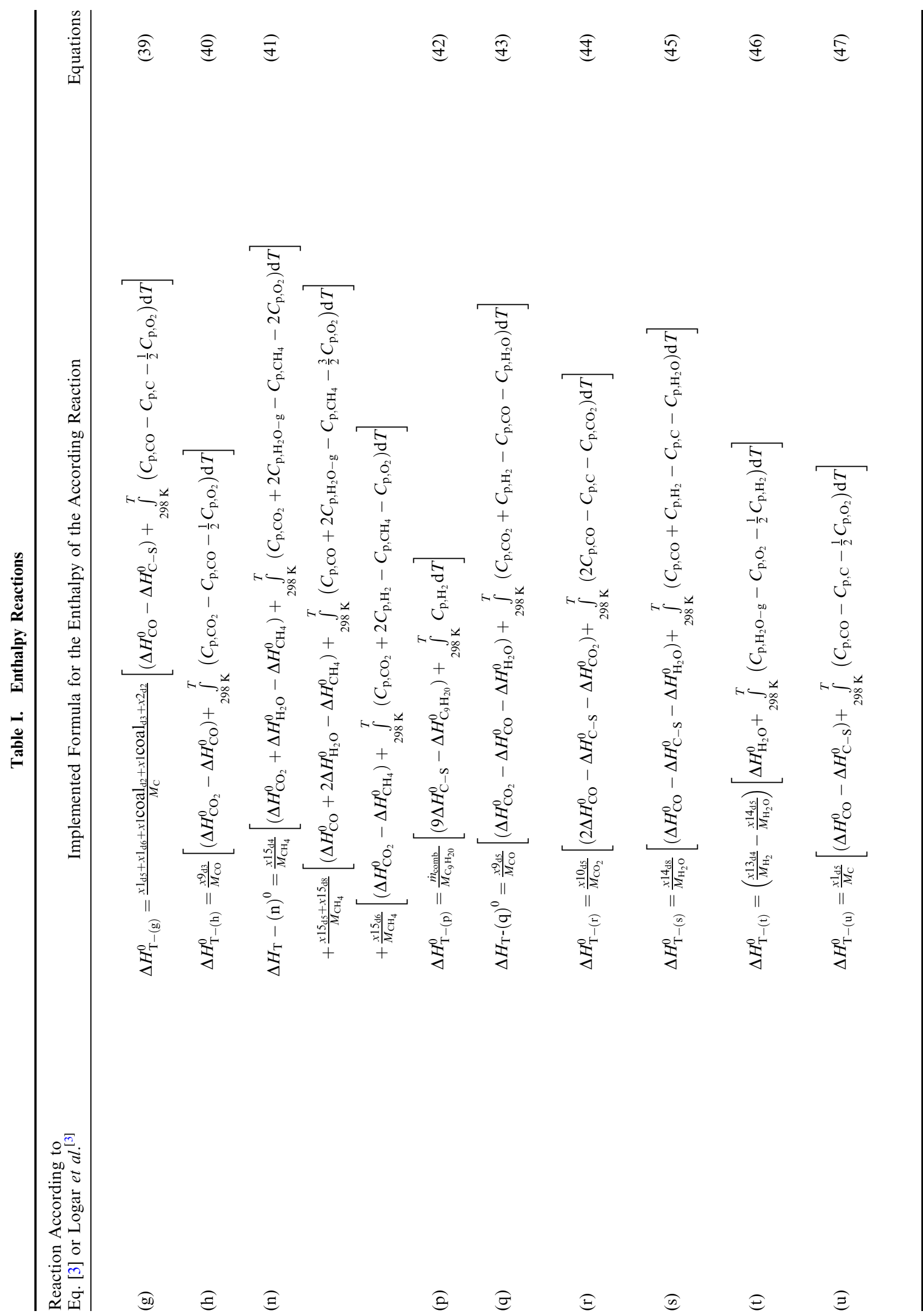


with $\Delta H_{298}^{0}$ being the standard enthalpy of formation at standard temperature and pressure. By using the actual variables and reaction indices presented in Eq. [3] and by Logar et al., ${ }^{[3]}$ the change of enthalpy is obtained for the implemented reactions according to Eqs. [39] through [47] in Table I.

Compared to Logar et al. ${ }^{[3]}$ the enthalpy of the reaction of the combustibles $\mathrm{C}_{9} \mathrm{H}_{20}$ is calculated according to the dissociation reaction in Eq. [3p], where $\mathrm{C}_{9} \mathrm{H}_{20}$ and $\mathrm{C}$ are assumed with standard temperature. All other reaction enthalpies $\Delta H_{\mathrm{T}-(\mathrm{a})}^{0}$ to $\Delta H_{\mathrm{T}-(\mathrm{m})}^{0}$ are implemented according to Logar et al. ${ }^{[3]}$ with adaptions in the equations for $\Delta H_{\mathrm{T}-(\mathrm{g})}^{0}$ and $\Delta H_{\mathrm{T}-(\mathrm{h})}^{0}$.

The energy of the chemical reactions are allocated to the heat balance of the corresponding zones $1 \mathrm{Sc}$ and gas via the heats $Q_{\text {ISc-chem }}$ and $Q_{\text {gas-chem }}$ according to Eqs. [48] and [49]:

$$
\begin{aligned}
& Q_{\mathrm{ISc}-\mathrm{chem}}=\sum_{\operatorname{var}_{\mathrm{i}}=(\mathrm{a})}^{(\mathrm{m})} \Delta H_{\mathrm{T}-\left(\mathrm{var}_{\mathrm{i}}\right)}^{0}-\Delta H_{\mathrm{T}-(\mathrm{h})}^{0}, \\
& Q_{\text {gas-chem }}=\sum_{\operatorname{var}_{\mathrm{i}}=(\mathrm{n})}^{(\mathrm{u})} \Delta H_{\mathrm{T}-\left(\mathrm{var}_{\mathrm{i}}\right)}^{0}+\Delta H_{\mathrm{T}-(\mathrm{h})}^{0},
\end{aligned}
$$

where $Q_{\text {gas-chem }}$ is a further summand in the balance of $Q_{\text {gas }}$, which is implemented according to Logar et al. ${ }^{[2]}$

\section{RESULTS AND DISCUSSION}

This section present the simulation results, which are relevant for the modeling and simulation of the EAF

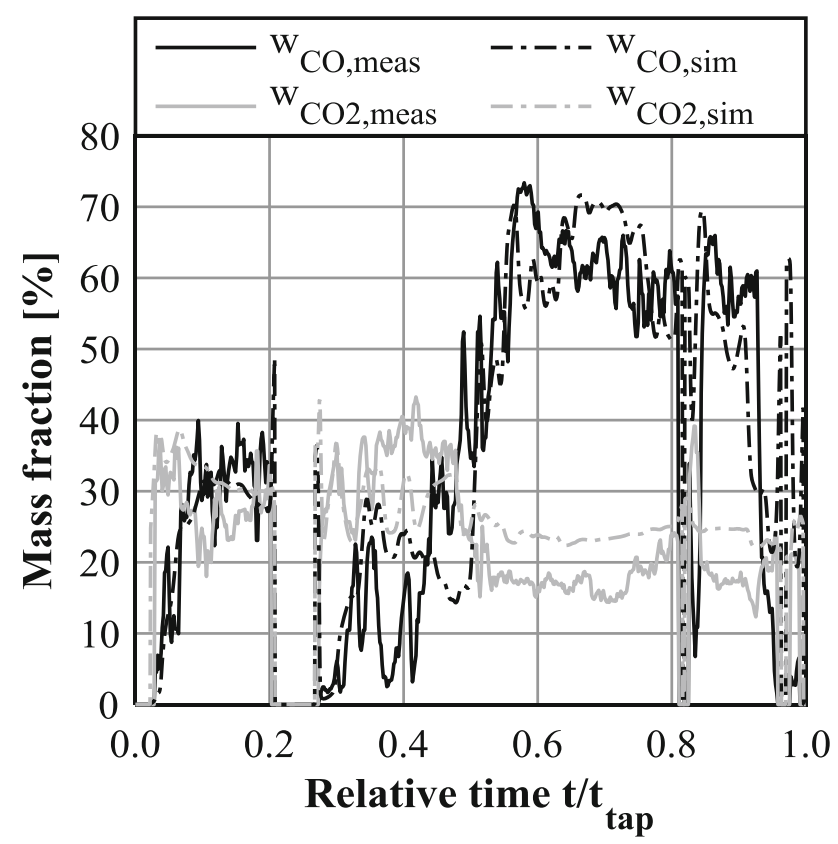

Fig. 2-Measured (meas) and simulated (sim) mass fractions $w_{i}$ of $\mathrm{CO}$ and $\mathrm{CO}_{2}$ in the off-gas of a single heat. off-gas. The results are compared to measured data from an industrial scale EAF with a tapping weight of approximately $140 \mathrm{t}$. The process simulation was performed with MATLAB R2015b on a PC with $3.4 \mathrm{GHz}$, 16 GB RAM, and Windows 764 bit. The relative integration tolerance was set to $10^{-9}$. For the simulation, the input data for scrap and operational data for power and mass flows into the EAF were used, while the hot heel was assumed constant with a mass of $30 \mathrm{t}$. The

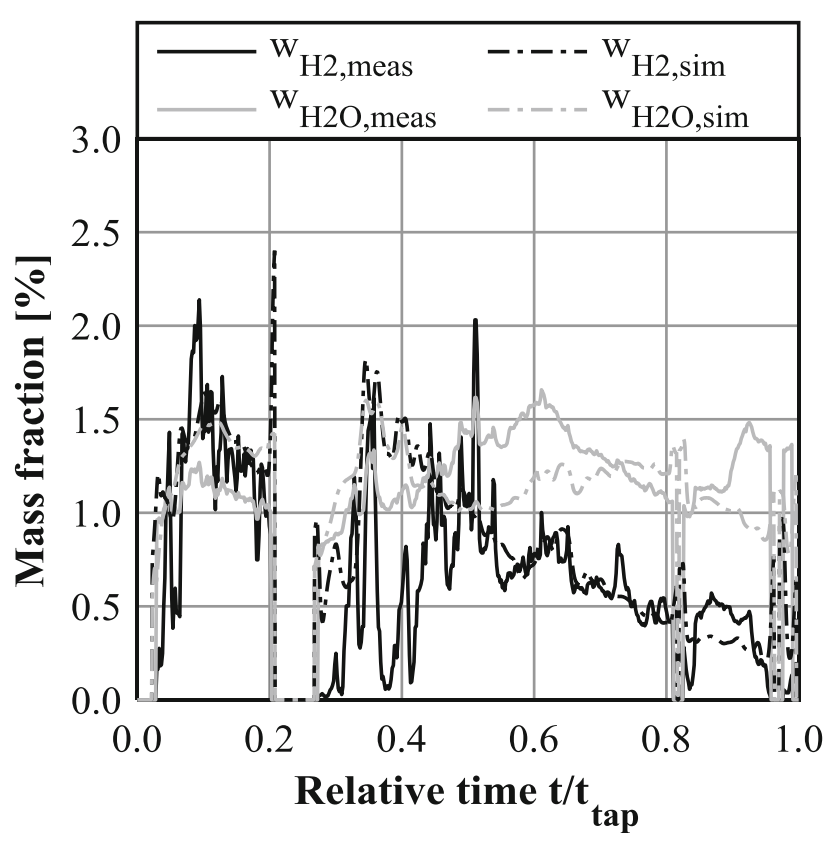

Fig. 3-Measured (meas) and simulated (sim) mass fractions $w_{i}$ of $\mathrm{H}_{2}$ and $\mathrm{H}_{2} \mathrm{O}$ in the off-gas of a single heat.

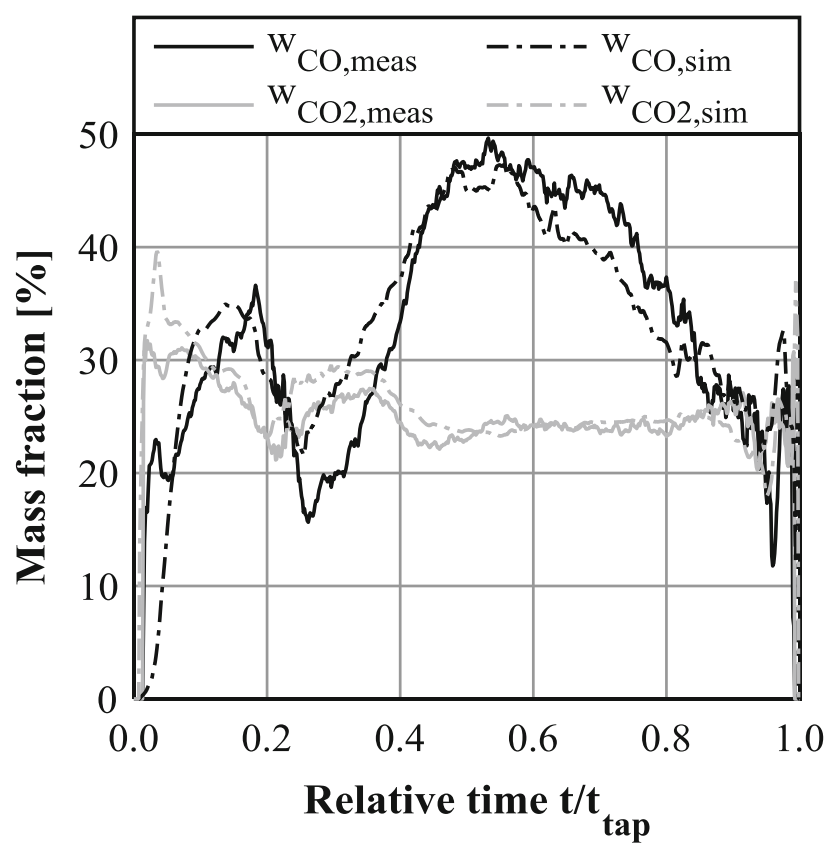

Fig. 4-Averaged measured (meas) and simulated (sim) mass fractions $w_{i}$ of $\mathrm{CO}$ and $\mathrm{CO}_{2}$ in the off-gas for 126 heats. 


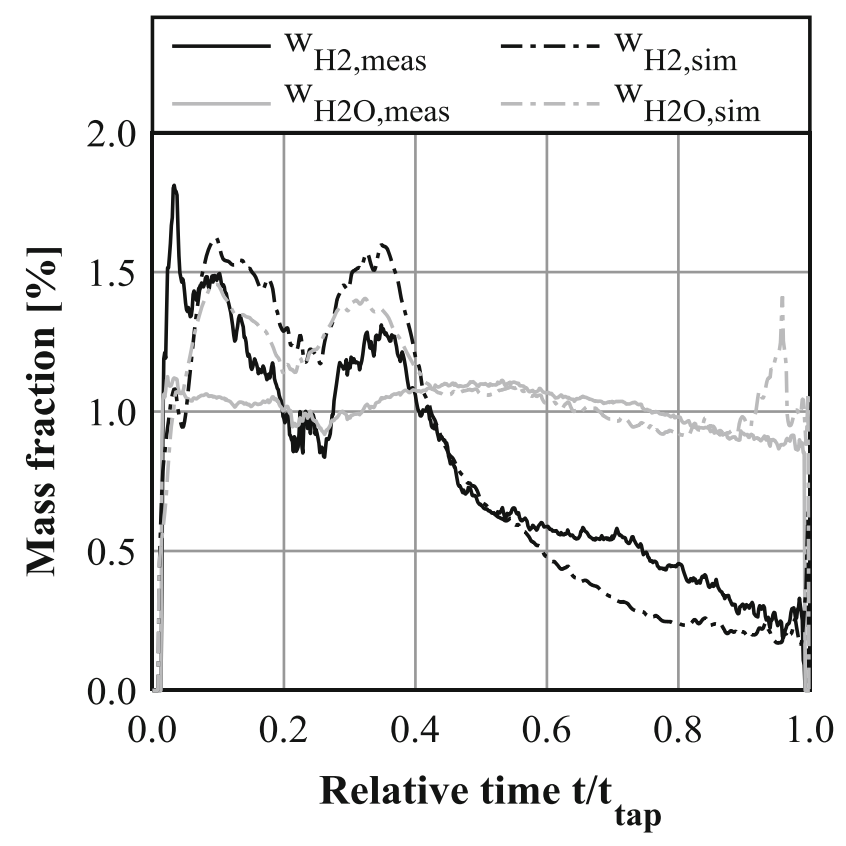

Fig. 5-Averaged measured (meas) and simulated (sim) mass fractions $w_{i}$ of $\mathrm{H}_{2}$ and $\mathrm{H}_{2} \mathrm{O}$ in the off-gas for 126 heats.

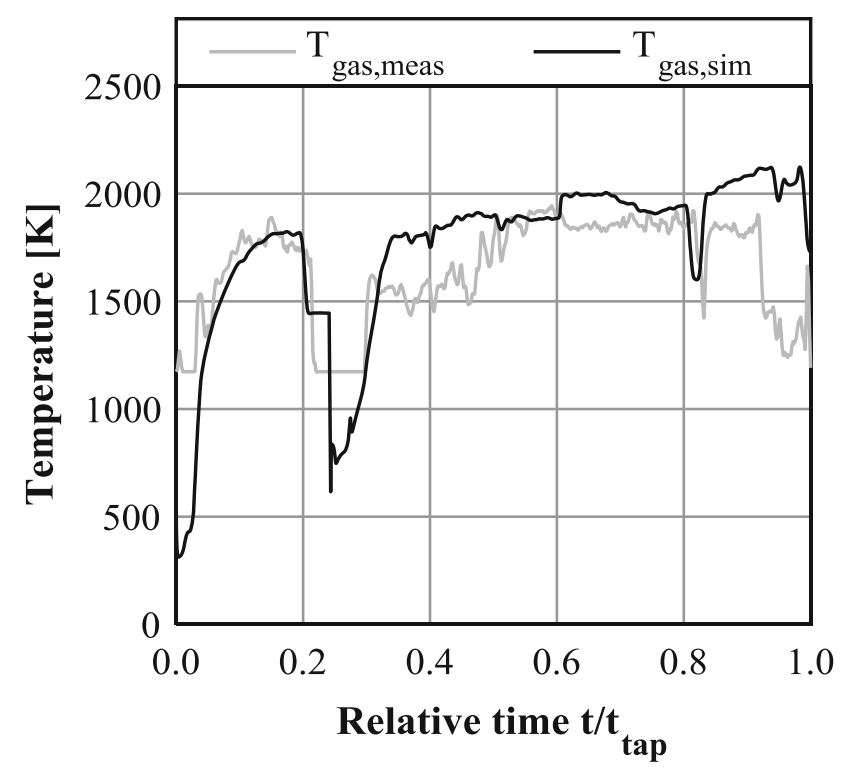

Fig. 6-Measured (meas) and simulated (sim) off-gas temperature for a single heat.

operational data used have a resolution of 5 seconds and were evaluated with an interpolation approach for each integration time step to determine the input mass flows and powers. In total, 126 heats were simulated and evaluated in terms of energy and mass balance. Furthermore, the steel, slag, and gas compositions and temperatures were compared.

In the following, the results from single heats are compared as well as averaged results from all 126 heats. Thereby, transient behavior that cannot be reproduced

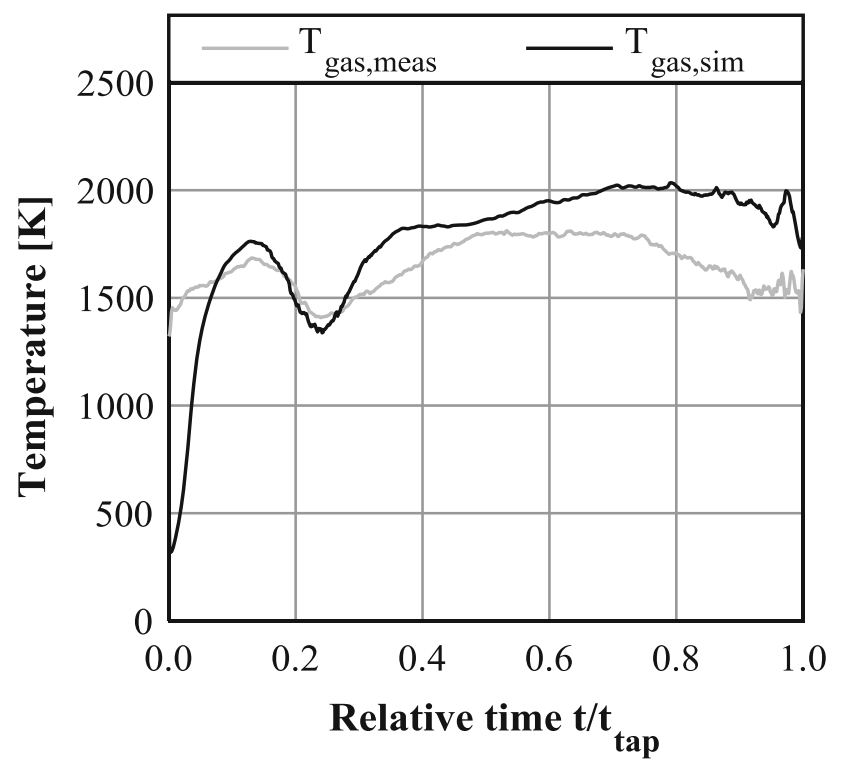

Fig. 7-Averaged measured (meas) and simulated (sim) off-gas temperature for 126 heats.

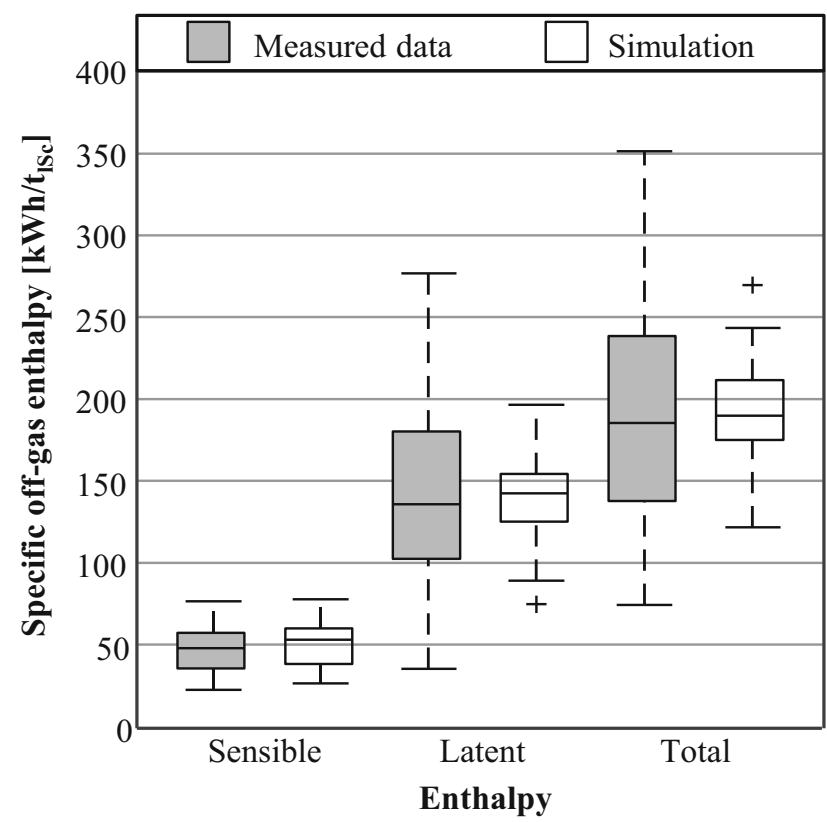

Fig. 8-Boxplots of the measured and simulated off-gas enthalpy of 126 heats.

by the simulation is smoothed over and leads to a better comparability of the results.

Figure 2 shows the measured (meas) and simulated (sim) mass fractions of $\mathrm{CO}$ in black and $\mathrm{CO}_{2}$ in gray as parts of the gas phase for a single heat. The charging of the second scrap basket is obvious at 20 pct relative time. The curves for $\mathrm{CO}$ are in the same range of magnitude with the biggest differences of 20 pct occurring at approximately 38 and 50 pet relative process time. For $\mathrm{CO}_{2}$, the mass fractions are in the same range 
of magnitude during the melting of the first scrap basket. During the melting of the second scrap basket and the refining phase, the simulated mass fraction is about 8 pct higher than the measured fraction. In this case, the post-combustion, carbon reactions in the EAF, and the equilibrium reactions need further adjustment but the results are already satisfactory. Further conclusions can be drawn by analyzing the mass fractions of $\mathrm{H}_{2}$ and $\mathrm{H}_{2} \mathrm{O}$.

Therefore, Figure 3 shows their mass fractions, as these components were added to the gas phase simulation and are relevant for the equilibrium reactions. These components occur in small amounts compared to

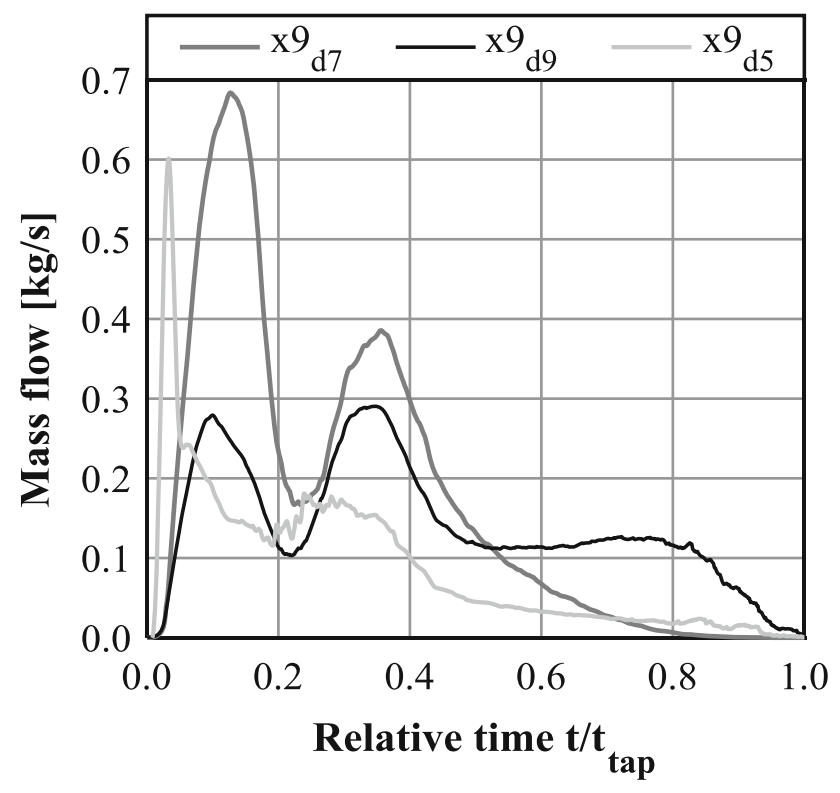

Fig. 9-Averaged $\mathrm{CO}$ mass flows of the equilibrium reactions from Boudouard $\left(x 9_{\mathrm{d} 7}\right)$, the heterogeneous water-gas reaction $\left(x 9_{\mathrm{d} 9}\right)$, and the homogeneous water-gas reaction $\left(x 9_{\mathrm{d} 5}\right)$.

Table II. Reaction Rates Used in the Model

\begin{tabular}{llllll}
\hline $\mathrm{kd}_{\mathrm{C}-\mathrm{L}}$ & $\mathrm{kd}_{\mathrm{C}-\mathrm{D}}$ & $\mathrm{kd}_{\mathrm{C}-1}$ & $\mathrm{kd}_{\mathrm{C}-2}$ & $\mathrm{kd}_{\mathrm{C}-3}$ & $\mathrm{kd}_{\mathrm{C}-4}$ \\
0.025 & 35 & 60 & 55 & 0.035 & 0.0035 \\
$\mathrm{kd}_{\mathrm{C}-5}$ & $\mathrm{kd}_{\mathrm{C}-6}$ & $\mathrm{kd}_{\text {gas-(q) }}$ & $\mathrm{kd}_{\text {gas-(r) }}$ & $\mathrm{kd}_{\text {gas-(s) }}$ & $\mathrm{kd}_{\mathrm{CO}-1}$ \\
0.06 & 0.017 & 1.35 & 0.0006 & 0.065 & 0.95 \\
$\mathrm{kd}_{\mathrm{Mn}-1}$ & $\mathrm{kd}_{\mathrm{H}_{2}-\text { post }}$ & $\mathrm{kd}_{\mathrm{H}_{2} \mathrm{O}}$ & $\mathrm{kd}_{\mathrm{CH}_{4}-\text { post }}$ & $\mathrm{kd}_{\text {comb }}$ & \\
1 & 0.1 & 1 & 5 & 0.028 & \\
\hline
\end{tabular}

All rates are in $\mathrm{kg} \mathrm{s}^{-1}$.
$\mathrm{CO}$ and $\mathrm{CO}_{2}$, so that the scale of the $y$-axis has to be adjusted accordingly. The course of the measured and simulated mass fractions are in the same range of magnitude with a bigger difference in $\mathrm{H}_{2}$ at 40 pct process time, which can be associated with non-stationary behavior of the melting.

For a further comparison of the results with less influence of instationarities, the averaged mass fractions of $\mathrm{CO}$ and $\mathrm{CO}_{2}$ for 126 heats are presented in Figure 4. It is obvious that the simulated fraction of $\mathrm{CO}$ is approximately $10 \mathrm{pct}$ higher than the measured fraction after charging the second scrap basket. In contrast, the simulated $\mathrm{CO}$ fraction is below the measured fraction during the refining phase. The conversion of $\mathrm{CO}$ in the EAF through combustion and decarburization needs to be shifted further to the refining. In case of $\mathrm{CO}_{2}$, the simulated fractions are close to the measured values.

The averaged mass fractions of $\mathrm{H}_{2}$ and $\mathrm{H}_{2} \mathrm{O}$ are presented in Figure 5. For $\mathrm{H}_{2} \mathrm{O}$, the simulation results are higher than the measured values at 10 and $30 \mathrm{pct}$ process time. Here, the natural gas injection is at a maximum and more water vapor is created through $\mathrm{CH}_{4}$ combustion in the simulation than in the real process. Further adjustment of the $\mathrm{CH}_{4}$ reactions is necessary, but the results are already satisfactory.

The chemical reactions in the gas phase have an influence on the gas temperature, which is shown in Figure 6 for a single heat and averaged for all simulated heats in Figure 7. While the simulated temperature curve for a single heat shows a satisfactory result, the average temperature shows bigger deviations of the simulated off-gas temperature. Especially during the melting of the second scrap basket and the refining phase, the simulated temperature is always higher than the measured temperature. To investigate the influence of the temperature on the total energy balance of the EAF, the specific off-gas enthalpy of all 126 heats is given in Figure 8 as boxplots. The off-gas temperature difference is visible in the higher sensible enthalpy output for the simulation. Compared to the latent enthalpy with medians at $140 \mathrm{kWh} \mathrm{t}^{-1}$, which is the chemical energy of $\mathrm{CO}, \mathrm{H}_{2}$, and $\mathrm{CH}_{4}$, the sensible

Table IV. Values of Other Parameters Used in the Model

\begin{tabular}{lll}
\hline$T_{\text {air }}$ & $T_{\text {melt,sSc }}$ & $K_{\mathrm{PR}}$ \\
$298 \mathrm{~K}$ & $1809 \mathrm{~K}$ & $0.3 \mathrm{~kg} \mathrm{~s}^{-1} \mathrm{~Pa}^{-1}$ \\
$h_{\mathrm{d}}$ & $u_{2}$ & $k_{\mathrm{u}}$ \\
$0.65 \mathrm{~m}$ & $0.3 \mathrm{~m}$ & 6.44 \\
$p^{0}$ & $101.3 \mathrm{kPa}$ & \\
\hline
\end{tabular}

Table III. Fractions Used in the Model

\begin{tabular}{|c|c|c|c|c|c|}
\hline $\begin{array}{l}w_{\mathrm{O}_{2}-\text { air }} \\
0.23 \\
K_{\text {leakair }-\mathrm{O}_{2}-\mathrm{CO}(1)} \\
0.4\end{array}$ & $\begin{array}{l}w_{\mathrm{N}_{2}-\text { air }} \\
0.77 \\
K_{\text {leakair-O }}-\mathrm{CO}(2) \\
0.3\end{array}$ & $\begin{array}{l}w_{\mathrm{N}_{2}-\text { in-natgas }} \\
0.25 \\
K_{\mathrm{O}_{2}-\mathrm{CO}} \\
0.15\end{array}$ & $\begin{array}{l}w_{\mathrm{CH}_{4}-\text { in-natgas }} \\
0.75 \\
K_{\mathrm{O}_{2}-\mathrm{CO}_{2}} \\
0.15\end{array}$ & $\begin{array}{l}w_{\mathrm{N}_{2}-\text { in-oxygen }} \\
0.026 \\
K_{\mathrm{O}_{2}-\text { post }-\mathrm{CO}} \\
0.01\end{array}$ & $\begin{array}{l}w_{\mathrm{O}_{2}-\text { in-oxygen }} \\
0.93\end{array}$ \\
\hline $\begin{array}{l}K_{\text {burn-(n1) }} \\
0.55\end{array}$ & $\begin{array}{l}K_{\text {burn-(n2) }} \\
0.3\end{array}$ & $\begin{array}{l}K_{\text {burn-(n3) }} \\
0.15\end{array}$ & $\begin{array}{l}x_{(\mathrm{q})} \\
0.8\end{array}$ & $\begin{array}{l}x_{(\mathrm{r})} \\
0.066\end{array}$ & $\begin{array}{l}x_{(\mathrm{s})} \\
0.134\end{array}$ \\
\hline
\end{tabular}


Table V. Used Values of Thermodynamical and Physical Substance Constants $\left(M_{i}\right.$ in $\mathrm{kg} \mathrm{mol}^{-1}, \rho_{i}$ in $\mathrm{kg} \mathrm{m}^{-3}, C_{\mathrm{p}, \mathrm{i}}$ in $\mathrm{kJ} \mathrm{mol}{ }^{-1} \mathrm{~K}^{-1}, \Delta H_{i}^{0}$ in $\mathrm{kJ} \mathrm{mol}^{-1}$ and $\lambda_{i}$ in $\left.\mathrm{kJ} \mathrm{mol}^{-1}\right)$

\begin{tabular}{|c|c|c|c|c|c|}
\hline$M_{\mathrm{C}}$ & $M_{\mathrm{CO}}$ & $M_{\mathrm{CO}_{2}}$ & $M_{\mathrm{N}_{2}}$ & $M_{\mathrm{O}_{2}}$ & $M_{\mathrm{H}_{2}}$ \\
\hline 0.012 & 0.028 & 0.044 & 0.028 & 0.032 & 0.002 \\
\hline$M_{\mathrm{H}_{2} \mathrm{O}}$ & $M_{\mathrm{CH}_{4}}$ & $M_{\mathrm{Fe}}$ & $M_{\mathrm{Si}}$ & $M_{\mathrm{Cr}}$ & $M_{\mathrm{Mn}}$ \\
\hline 0.018 & 0.016 & 0.0559 & 0.0281 & 0.052 & 0.0549 \\
\hline$M_{\mathrm{P}}$ & $M_{\mathrm{FeO}}$ & $M_{\mathrm{SiO}_{2}}$ & $M_{\mathrm{MnO}}$ & $M_{\mathrm{Cr}_{2} \mathrm{O}_{3}}$ & $M_{\mathrm{P}_{2} \mathrm{O}_{5}}$ \\
\hline 0.031 & 0.0718 & 0.0601 & 0.0709 & 0.1520 & 0.1419 \\
\hline$M_{\mathrm{Al}_{2} \mathrm{O}_{3}}$ & $M_{\mathrm{CaO}}$ & $M_{\mathrm{MgO}}$ & $M_{\mathrm{C}_{9} \mathrm{H}_{20}}$ & $M_{\text {leakair }}$ & \\
\hline $0.102^{3}$ & 0.0561 & 0.0403 & 0.1283 & 0.0289 & \\
\hline$C_{\mathrm{p}, \mathrm{C}}$ & $C_{\mathrm{p}, \mathrm{CO}}$ & $C_{\mathrm{p}, \mathrm{CO}_{2}}$ & $C_{\mathrm{p}, \mathrm{N}_{2}}$ & $C_{\mathrm{p}, \mathrm{O}_{2}}$ & $C_{\mathrm{p}, \mathrm{H}_{2}}$ \\
\hline 0.0085 & 0.0291 & 0.0381 & 0.0291 & 0.0294 & $\begin{array}{l}0.029 \\
0.029\end{array}$ \\
\hline$C_{\mathrm{p}, \mathrm{H}_{2} \mathrm{O}-\mathrm{g}}$ & $C_{\mathrm{p}, \mathrm{CH}_{4}}$ & $C_{\mathrm{p}, \mathrm{Fe}}$ & $C_{\mathrm{p}, \mathrm{Si}}$ & $C_{\mathrm{p}, \mathrm{Cr}}$ & $C_{\mathrm{p}, \mathrm{Mn}}$ \\
\hline $\begin{array}{l}\mathrm{p}, \mathrm{H}_{2} \mathrm{O}-\mathrm{g} \\
0.0342\end{array}$ & 0.035 & 0.0251 & 0.0197 & 0.0233 & 0.0263 \\
\hline$C_{\mathrm{p}, \mathrm{P}}$ & $C_{\mathrm{p}, \mathrm{FeO}}$ & $C_{\mathrm{p}, \mathrm{SiO}_{2}}$ & $C_{\mathrm{p}, \mathrm{MnO}}$ & $C_{\mathrm{p}, \mathrm{Cr}_{2} \mathrm{O}_{3}}$ & $C_{\mathrm{p}, \mathrm{P}_{2} \mathrm{O}_{5}}$ \\
\hline $\begin{array}{l}0.0212 \\
0.02\end{array}$ & 0.048 & 0.0448 & 0.0431 & $0.1097^{3}$ & 0.2115 \\
\hline$C_{\mathrm{p}, \mathrm{C}_{9} \mathrm{H}_{20}}$ & $C_{\mathrm{p}, \mathrm{H}_{2} \mathrm{O}-1}$ & $C_{\mathrm{p}, \mathrm{sSc}}$ & $C_{\mathrm{p}, 1 \mathrm{Sc}}$ & $C_{\mathrm{p}, \mathrm{sSl}}$ & $C_{\mathrm{p}, \mathrm{IS} 1}$ \\
\hline 0.2833 & 0.075 & 0.039 & 0.047 & 0.025 & 0.047 \\
\hline$C_{\mathrm{p}, \mathrm{gas}}$ & $\lambda_{\mathrm{sSc}}$ & $\lambda_{\mathrm{sS} 1}$ & $\lambda_{\mathrm{C}}$ & $\rho_{\mathrm{CH}_{4}}$ & $\rho_{\mathrm{CO}}$ \\
\hline 0.03 & 15.4 & 12.66 & 117 & 0.72 & 1.25 \\
\hline $\begin{array}{l}\rho_{\mathrm{CO}_{2}} \\
1.98\end{array}$ & $\begin{array}{l}\rho_{\mathrm{N}_{2}} \\
1.25\end{array}$ & $\begin{array}{l}\rho_{\mathrm{O}_{2}} \\
1.429\end{array}$ & $\begin{array}{l}\rho_{\mathrm{H}_{2}} \\
0.0899\end{array}$ & $\begin{array}{l}\rho_{\mathrm{H}_{2} \mathrm{O}} \\
0.59\end{array}$ & \\
\hline$\Delta H_{\mathrm{C}-\mathrm{S}}^{0}$ & $\Delta H_{\mathrm{CO}}^{0}$ & $\Delta H_{\mathrm{CO}}^{0}$ & $\Delta H_{\mathrm{H}_{2} \mathrm{O}}^{0}$ & $\Delta H_{\mathrm{CH}_{4}}^{0}$ & $\Delta H_{\mathrm{C}_{0} \mathrm{H}_{2}}^{0}$ \\
\hline$-27^{C-S}$ & -117 & -396 & -247 & $-91^{\mathrm{CH}_{4}}$ & $2.256^{{ }^{20}}$ \\
\hline
\end{tabular}

enthalpy with medians at around $50 \mathrm{kWh} \mathrm{t}^{-1}$ is lower. The difference of the simulated off-gas temperature has less influence on the off-gas energy output than a difference in the simulated off-gas composition compared to the real process.

Finally, the averaged mass flows of $\mathrm{CO}$ for the newly implemented chemical equilibrium reactions are shown in Figure 9. During the whole process, the equilibrium reactions lead to a production of $\mathrm{CO}$. The amounts of up to $0.7 \mathrm{~kg} \mathrm{~second}^{-1}$ demonstrate the relevance of considering these reactions in the gas phase modeling.

It can be seen that the consideration of further gas components and equilibrium reactions in the gas phase lead to a better gas phase simulation in a dynamic process simulation model of an EAF. This is important, as the off-gas temperature and composition are continuously measurable process values and represent one of the biggest energy outputs of the EAF.

Finally, the duration of the simulation is important for the applicability of the dynamic process model. The further enhancement of the model leads to a higher complexity, while the ODE-solver accelerates the simulation. For a single heat, the simulation time is between 65 and 85 seconds. Due to the ability of parallel computing, the 126 heats are simulated on four processor cores in less than 1 hour. That means that the model is applicable for online process optimization.

\section{CONCLUSION}

In this paper, the enhancement of the gas phase of the dynamic EAF process model by Logar et al ${ }^{[2,3]}$ is presented. The gas components $\mathrm{H}_{2}, \mathrm{H}_{2} \mathrm{O}$, and $\mathrm{CH}_{4}$ were included in the gas phase modeling. These components were integrated into the calculation of chemical reactions under consideration of the equilibrium reactions of
Boudouard and the water-gas reaction. To prevent the increase of simulation time due to the higher complexity, the model was re-implemented in MATLAB to use the more efficient ODE-solver ode15s for stiff ODE-systems.

The presented results of the enhanced EAF model were compared to measured data from an industrial scale EAF. The off-gas mass fractions for single heats as well as averaged data show a satisfactory similarity. The simulation of the gas phase temperature shows bigger differences, which have a negligible influence on the simulated off-gas energy output. The implemented equilibrium reactions show their significance on the $\mathrm{CO}$ production in the EAF. Further optimization is still necessary. Especially the conversion of $\mathrm{C}$ through combustion and decarburization has to be improved. Therefore, further measurements and data are necessary, especially concerning the slag mass and mass of the hot heel. In the future, the model has to prove its applicability for different EAFs and thereby the extrapolation capability for offline investigations.

The simulation results were obtained in about 1 minute for each heat, so that the model is applicable for online optimization. In addition, the parallel computing allows the simulation of hundreds of different settings, input materials, or operation strategies within a reasonable time. With that, the model is appropriate for operator training and offline investigations on input materials and modes of operation to reduce costs and energy consumption and increase the energy and resource efficiency.

\section{APPENDICES}

Table II gives the reaction rates $k d$ used in the model. In Table III, all necessary fractions (weight fractions $w$, fraction constants $K$ for the reactions, and volume 
fractions $x$ for the reaction volumes) are listed. Table IV contains all other constant parameters used in the model. In Table $\mathrm{V}$, the used values of thermodynamical and physical constants (e.g., molar masses $M_{i}$ and heat capacities $C_{p, i}$ ) are listed.

All values are adopted from Logar et al., ${ }^{[2,3]}$ partially adapted and/or supplemented. The values were validated and parameterized using industrial furnace data.

\section{LIST OF SYMBOLS}

\section{GREEK LETTERS}

$\lambda$ Latent heat of fusion

$v \quad$ Stoichiometric coefficient

$v^{\prime} \quad$ Stoichiometric coefficient of the forward reaction

$v^{\prime \prime}$ Stoichiometric coefficient of the backward reaction $\rho \quad$ Density

\section{LATIN LETTERS}

$\Delta H_{T}^{0}$
$\Delta \mathrm{H}_{298}^{0}$
$\Delta H_{\mathrm{T}-()}^{0}$
$\Delta_{\mathrm{R}} G^{0}$
$A$
$B$
$c$
$C$
$C_{\mathrm{p}}$
$D$
$h_{\mathrm{d}}$
$\mathrm{kd}_{\mathrm{C}-3}$
$\mathrm{kd}_{\mathrm{C}-4}$
$k_{\mathrm{b}}$
$k_{\mathrm{f}}$
$k_{\mathrm{u}}$
$\mathrm{kd}_{\mathrm{C}-2}$
$\mathrm{kd}_{\mathrm{C}-1}$

Reaction enthalpy at temperature $T$ and standard pressure $p^{0}$

Standard formation enthalpy at standard temperature $(298 \mathrm{~K})$ and standard pressure $p^{0}$

Standard formation enthalpy at $T$ and standard pressure $p^{0}$ for a specific reaction

Free standard enthalpy

Reacting element of the reaction $\left|v_{\mathrm{A}}\right| A+\left|v_{\mathrm{B}}\right| B \rightarrow\left|v_{\mathrm{C}}\right| C+\left|v_{\mathrm{D}}\right|$

Reacting element of the reaction

$\left|v_{\mathrm{A}}\right| A+\left|v_{\mathrm{B}}\right| B \rightarrow\left|v_{\mathrm{C}}\right| C+\left|v_{\mathrm{D}}\right| D$

Concentration

Reagent of the reaction

$\left|v_{\mathrm{A}}\right| A+\left|v_{\mathrm{B}}\right| B \rightarrow\left|v_{\mathrm{C}}\right| C+\left|v_{\mathrm{D}}\right| D$

Heat capacity

Reagent of the reaction

$\left|v_{\mathrm{A}}\right| A+\left|v_{\mathrm{B}}\right| B \rightarrow\left|v_{\mathrm{C}}\right| C+\left|v_{\mathrm{D}}\right| D$

Characteristic dimension of duct are

at the slip gap

Reaction rate constant

Backward reaction rate constant

Forward reaction rate constant

Dimensionless constant

Empirical velocity coefficient

Empirical velocity coefficient for

oxidation of dissolved $\mathrm{C}$ with injected $\mathrm{O}_{2}$ to $\mathrm{CO}$

Empirical velocity coefficient for oxidation of dissolved $\mathrm{C}$ with injected $\mathrm{O}_{2}$ to $\mathrm{CO}_{2}$

Empirical velocity coefficient for

dissolving of injected $\mathrm{C}$

Empirical velocity coefficient for

dissolving of $\mathrm{C}$ from charged coal

Empirical velocity coefficient for oxidation of injected $\mathrm{C}$ with $\mathrm{O}_{2}$ from gas phase to $\mathrm{CO}$
$\mathrm{kd}_{\mathrm{C}-6}$
$\mathrm{kd}_{\mathrm{C}-\mathrm{D}}$
$\mathrm{kd}_{\mathrm{C}-\mathrm{L}}$
$\mathrm{kd}_{\mathrm{CO}-1}$

$\mathrm{kd}_{\mathrm{CH}_{4}-\text { post }}$

$\mathrm{kd}_{\text {comb }}$

$\operatorname{kd}_{\text {gas- }}(\xi)$

$\mathrm{kd}_{\mathrm{H}_{2}-\text { post }}$

$\mathrm{kd}_{\mathrm{H}_{2} \mathrm{O}}$

$\mathrm{kd}_{\mathrm{Mn}-1}$

K

$K_{\text {burn-(n) }}$

$K_{\text {leakair- } \mathrm{O}_{2}-\mathrm{CO}(1)}$

$K_{\text {leakair- } \mathrm{O}_{2}-\mathrm{CO}(2)}$

$K_{\mathrm{O}_{2}-\mathrm{CH}_{4}-\mathrm{inj}}$

$K_{\mathrm{O}_{2}-\mathrm{CO}}$

$K_{\mathrm{O}_{2}-\mathrm{CO}_{2}}$

$K_{\mathrm{O}_{2}-\text { post-CO }}$

$K_{\mathrm{c}}$ or $K_{\mathrm{c}-(\xi)}$

$K_{\mathrm{p}}$

$K_{\mathrm{PR}}$

$K_{\text {sSc-1Sc }}$

$m$

$\dot{m}$

$\dot{m}_{\mathrm{el}}$

$\dot{m}_{\text {water-in }}$

$\dot{m}_{\text {solidify }}$
Empirical velocity coefficient for oxidation of $\mathrm{C}$ from charged coal with $\mathrm{O}_{2}$ from gas phase to $\mathrm{CO}$

Empirical velocity coefficient for dissolving $\mathrm{C}$ in melt

Empirical velocity coefficient for decarburization

Empirical velocity coefficient for oxidation of $\mathrm{CO}$ with $\mathrm{O}_{2}$ from the gas phase to $\mathrm{CO}_{2}$

Empirical velocity coefficient for oxidation of $\mathrm{CH}_{4}$ with $\mathrm{O}_{2}$ from the gas phase

Empirical velocity coefficient for the oxidation of combustible material Empirical velocity coefficient of equilibrium reaction in gas phase $(\xi=(\mathrm{q}),(\mathrm{r}),(\mathrm{s}))$

Empirical velocity coefficient for oxidation of $\mathrm{H}_{2}$ with $\mathrm{O}_{2}$ from the gas phase to $\mathrm{H}_{2} \mathrm{O}$

Empirical velocity coefficient for the dissociation of water

Empirical velocity coefficient for $\mathrm{MnO}$ decarburization

Fractions of mass, which is available for a specific reaction

Fraction of the burner reaction volume for the reaction $\left(\mathrm{n}_{1}\right),\left(\mathrm{n}_{2}\right)$, or $\left(\mathrm{n}_{3}\right)$

Fraction of $\mathrm{O}_{2}$, sucked in with leak air, available for the oxidation of injected $\mathrm{C}$ to $\mathrm{CO}$

Fraction of oxygen, sucked in with leak air, available for the oxidation of $\mathrm{C}$ from charged coal to $\mathrm{CO}$ Fraction of $\mathrm{O}_{2}$ injected with $\mathrm{CH}_{4}$ from burners available for the direct combustion of $\mathrm{CH}_{4}$

Fraction of injected $\mathrm{O}_{2}$ available for the oxidation of dissolved $\mathrm{C}$ to $\mathrm{CO}$ Fraction of injected $\mathrm{O}_{2}$ available for the oxidation of dissolved $\mathrm{C}$ to $\mathrm{CO}_{2}$ Fraction of injected $\mathrm{O}_{2}$ available for the oxidation of $\mathrm{CO}$ to $\mathrm{CO}_{2}$ Equilibrium constant $(\xi=(\mathrm{q}),(\mathrm{r})$,

(s))

Standard equilibrium constant

Constant defining the ration between mass flow and pressure

Correction factor, which includes the influence of solid scrap on the size of the reaction surface of $1 \mathrm{Sc}$

Mass

Mass flow

Mass flow of $\mathrm{C}$ released from

electrode consumption

Mass flow of water from electrode cooling

Mass flow from liquid to solid scrap if solidification occurs 


$M$
$p^{0}$
$p_{i}$
$p_{i}$
$p_{\mathrm{r}}$
$P$
$Q_{1 \mathrm{Sc}-\mathrm{chem}}$
$Q_{\text {gas-chem }}$
$\dot{Q}$
$r$
$r_{(\xi)}$
$R_{\mathrm{m}}$
$t$
$t_{\mathrm{tap}}$
$T$
$u_{1}$
$u_{2}$
$V$
$V_{(\xi)}$

$w$
$x_{(\xi)}$

$x i$
$X_{i}$
$X_{i}^{\mathrm{eq}}$
$Z$
$Z$
$Z_{\mathrm{St}-(\mathrm{n})}$

\section{SUBSCRIPTS-GREEK LETTERS}

$\xi$ Equilibrium reaction $(\xi=(\mathrm{q}),(\mathrm{r}),(\mathrm{s}))$

Pressure

Partial pressure of element $i$

Relative pressure in EAF

Power

phase

Heat flow

Molar reaction rate

Molar gas constant

Time

Tap time

Temperature

Off-gas mass flow

Slip gap width

Volume

reaction $(\xi=(\mathrm{q}),(\mathrm{r}),(\mathrm{s}))$

Weight fraction volume

Mass flow of element $i$

Molar fraction of element $i$ gas volume flows reaction $\left(\mathrm{n}_{1}\right),\left(\mathrm{n}_{2}\right)$, or $\left(\mathrm{n}_{3}\right)$ $j$

Pressure at standard conditions

Heat from chemical reactions in melt

Heat from chemical reaction in gas

Molar reaction rate $(\xi=(\mathrm{q}),(\mathrm{r}),(\mathrm{s}))$

Reaction volume of equilibrium

Fraction of reaction volume of

equilibrium reaction in the gas phase

Equilibrium molar fraction of

element $i$ in a specific reaction

Actual mixing fraction of the supplied

Stoichiometric mixing fraction of the

\section{SUBSCRIPTS-LATIN LETTERS}

$\begin{array}{ll}\text { air } & \text { Ambient air } \\ \text { addition } & \text { Added to a phase } x x \\ \mathrm{~b} & \text { Backward } \\ \mathrm{C}-\text {-inj } & \text { With lances injected carbon } \\ \mathrm{C}-\mathrm{D} & \text { Carbon dissolved in melt } \\ \mathrm{C}-\mathrm{L} & \text { Carbon present in EAF } \\ \mathrm{C}-\mathrm{S} & \text { Solid carbon } \\ \mathrm{CH}_{4} \text {-inj } & \text { Injected methane from burners } \\ \mathrm{CH}_{4} \text {-in-natgas } & \text { Methane in injected natural gas mass } \\ & \text { flow in burners } \\ \text { coal } & \text { Charged coal } \\ \mathrm{f} & \text { Forward } \\ \text { gas } & \text { Gas phase in the EAF } \\ \mathrm{H}_{2} \mathrm{O} \text {-gas } & \text { Gaseous water } \\ i & \text { Element }(i=1: \mathrm{C} \text { in EAF; } i=1 \text { coal: } \\ & \mathrm{C} \text { from charged coal; } i=2: \text { dissolved } \\ & \mathrm{C} ; i=9: \mathrm{CO} ; i=10: \mathrm{CO}_{2} ; i=11: \mathrm{N}_{2} ; \\ & \left.i=12: \mathrm{O}_{2}, \text { etc. }\right)\end{array}$

i,meas

i,sim

leakair

ISc

1S1

melt,sSc

$\mathrm{N}_{2}$-air

$\mathrm{N}_{2}$-in-natgas

$\mathrm{N}_{2}$-in-oxygen

$\mathrm{O}_{2}$-air

$\mathrm{O}_{2}-\mathrm{CH}_{4}$-inj

$\mathrm{O}_{2}$-gas

$\mathrm{O}_{2}$, lance

$\mathrm{O}_{2}$-in-oxygen

$\mathrm{O}_{2}$-post

$\mathrm{sSc}$

sSc, basket

$x x$

\section{ABBREVIATIONS}

BDF Backward differentiation formula

Comb Combustible material

EAF Electric arc furnace

El Electrode

1Sc Liquid scrap

1S1 Liquid slag

meas Measured

NDF Numerical differentiation formula

ODE Ordinary differential equations

sim Simulated

sSc Solid scrap

sSl Solid slag

St Stoichiometric

\section{REFERENCES}

1. International Energy Agency (IEA), ed.: World Energy Outlook 2014, IEA Publications, Paris, 2014.

2. V. Logar, D. Dovzan, and I. Skrjanc: ISIJ Int., 2012, vol. 52, pp. 402-12.

3. V. Logar, D. Dovzan, and I. Skrjanc: ISIJ Int., 2012, vol. 52, pp. 413-23.

4. V. Logar and I. Skrjanc: ISIJ Int., 2012, vol. 52, pp. 1225-32.

5. A. Fathi, Y. Saboohi, I. Skrjanc, and V. Logar: Steel Res. Int., 2017, DOI:10.1002/srin.201600083.

6. A. Fathi, Y. Saboohi, I. Skrjanc, and V. Logar: ISIJ Int., 2015, vol. 55, pp. $1353-60$.

7. F. Opitz and P. Treffinger: Metall. Mater. Trans. B, 2016, vol. 47B, pp. $1489-1503$.

8. S.A. Matson and W.F. Ramirez: Proc. 55th Electr. Furn. Conf., Iron and Steel Society, Warrendale, PA, 1997, pp. 675-85.

9. S.A. Matson, W.F. Ramirez, and P. Safe: Proc. 56th Electr. Furn. Conf., 16th Process Technol. Conf., Iron and Steel Society, Warrendale, PA, 1998.

10. R.D.M. MacRosty and C.L.E. Swartz: Ind. Eng. Chem. Res., 2005, vol. 44, pp. 8067-83. 
11. P. Nyssen, G. Monfort, J.L. Junque, M. Brimmeyer, P. Hubsch, and J.C. Baumert: Proc. 2nd Int. Conf. Model. Simul. Metall. Process. Steelmak. (SteelSim), The Austrian Society for Metallurgy and Materials (ASMET), Leoben, 2007, pp. 33-38.

12. T. Meier, V. Logar, T. Echterhof, I. Skrjanc, and H. Pfeifer: Steel Res. Int., 2015, vol. 87, pp. 581-88

13. T. Meier: Modellierung und Simulation des Elektrolichtbogenofens. Dissertation, RWTH Aachen University, Aachen, 2016.

14. K. Krüger and H. Pfeifer: Praxishandbuch Thermoprozesstechnik, Band 2: Anlagen, Komponenten, Sicherheit, $2^{\text {nd }}$ ed., Vulkan, Essen, 2011, pp. 43-80.
15. R.J. Kee, M.E. Coltrin, and P. Glarborg: Chemically Reacting Flow: Theory and Practice, Wiley-VCH, Hoboken, NJ, 2003.

16. M. Selby: Medium Model, MathWorks MATLAB Central, 2012, https://de.mathworks.com/matlabcentral/fileexchange/39349-mediummodel, Accessed 05 May 2016.

17. J.G. Bekker, I.K. Craig, and P.C. Pistorius: ISIJ Int., 1999, vol. 39 , pp. $23-32$.

18. T. Watanabe: ASEAN J. Chem. Eng., 2005, vol. 5, pp. 30-34.

19. N. Peters: Turbulent Combustion, Cambridge University Press, Cambridge, GB, 2000. 